\title{
Structure and dynamics of the Saharan atmospheric boundary layer during the West African monsoon onset: Observations and analyses from the research flights of 14 and 17 July 2006
}

\author{
Christophe Messager, ${ }^{a *}$ Douglas J. Parker, ${ }^{\mathrm{b}}$ O. Reitebuch, ${ }^{\mathrm{c}}$ A. Agusti-Panareda, ${ }^{\mathrm{d}}$ \\ Christopher M. Taylor ${ }^{\mathrm{e}}$ and J. Cuesta ${ }^{\mathrm{f}}$ \\ ${ }^{a}$ Laboratoire de Physique des Océans, UMR 6523, CNRS/IRD/IFREMER/UBO, Plouzané, France \\ ${ }^{\mathrm{b}}$ Institute for Climate and Atmospheric Science, School of Earth and Environment, University of Leeds, Leeds, United Kingdom \\ ${ }^{\mathrm{c} I n s t i t u t ~ f u ̈ r}$ Physik der Atmophäre, Deutsches Zentrum für Luft und Raumfahrt (DLR), Oberpfaffenhofen, Wessling, Germany \\ ${ }^{\mathrm{d}}$ European Centre for Medium-Range Weather Forecasts, Shinfield Park, Reading, United Kingdom \\ ${ }^{\mathrm{e}}$ Centre for Ecology and Hydrology, Wallingford, United Kingdom \\ ${ }^{\mathrm{f}}$ Laboratoire de Météorologie Dynamique/Institut Pierre et Simon Laplace, CNRS-INSU/ENS/EP/UPM, UMR 8539 - Ecole Polytechnique, \\ Palaiseau, France
}

\begin{abstract}
This paper presents the results of co-ordinated research flights over the Saharan heat-low, conducted during July 2006 as part of the African Monsoon Multidisciplinary Analysis (AMMA) Special Observing Periods. The flights consisted of a morning transect on 14 July 2006 with the Falcon F20 aircraft of the Deutsches Zentrum für Luft- und Raumfahrt (DLR), using the Doppler lidar WIND to observe the tropospheric winds, followed by an afternoon flight on 17 July with the BAe146 aircraft of the Facility for Airborne Atmospheric Measurements (FAAM) releasing a curtain of 16 dropsondes. Measurements from radiosondes at the Algerian stations of Tamanrasset and In Salah, as well as the CALIPSO spaceborne lidar, are analysed also. It is shown that the daytime Saharan atmospheric boundary layer exhibits a remarkable split structure, with a well-mixed convective layer lying beneath a residual layer whose dynamics appear to be more nearly laminar. Observations from Saharan radiosonde stations confirm that the Saharan residual boundary layer is, on some days, a persistent rather than a transient feature, and that on occasion the residual layer can last right through the day.

The broad features of the Saharan heat-low thermodynamics and winds are successfully captured by the ECMWF operational analyses and the discrepancies are quantified here. The lidar winds of 14 July confirm that the analysis represents the main airflows accurately, apart from the zone to the southeast of a mid-level trough, for which the southerly component of winds was underestimated by some $8 \mathrm{~m} \mathrm{~s}^{-1}$. On $17 \mathrm{July}$, the strengths of both the southwesterly monsoon and the northeasterly Harmattan winds were slightly underestimated also. The region of maximum boundary-layer temperature over the desert was around 1 degree too far north, and too broad in the analysis, while the equivalent potential temperature in the Saharan convective boundary layer was around $2 \mathrm{~K}$ lower than observed. The near-saturated layer observed at the top of the Saharan atmospheric boundary layer was underestimated also in the analysis, in horizontal extent and altitude. The intertropical front of 17 July was coincident with strong surface contrasts in vegetation and fluxes. On each study day the intertropical front in the analyses was around 1 degree further north than observed. Copyright (C) 2009 Royal Meteorological Society
\end{abstract}

KEY WORDS Convective and residual layers; Saharan heat-low dynamics; SHL radiosoundings and lidar profiles

Received 5 November 2008; Revised 2 June 2009; Accepted 3 June 2009

\section{Introduction}

The Sahara is the world's largest desert and has a strong influence on the regional climate of North and West Africa. However, due to the harsh environment, the atmosphere over the Sahara is one of the most poorly observed regions on Earth.

Interest in the atmosphere over the Sahara has been stimulated by recognition of its role in controlling the

\footnotetext{
${ }^{*}$ Correspondence to: C. Messager, Laboratoire de Physique des Océans, CNRS-INSU/IRD/IFREMER/UBO. UMR 6523 - BP 70 29280 Plouzané, France. E-mail: christophe.messager@ifremer.fr
}

climate of the highly populated Sahelian zone of West Africa. Walker and Rowntree (1977) and Charney (1975) showed that the Saharan conditions may have a strong control on the West African monsoon. The onset phase of the West African monsoon, associated with the northward seasonal displacement of the intertropical convergence zone (ITCZ) around late June (Sultan and Janicot, 2000, 2003), is essential for the populations of the Sahel because it determines the beginning of the rainy season. A number of studies (e.g. Sultan and Janicot, 2003; Drobinski et al., 2005a) have attempted to investigate the mechanisms controlling the monsoon onset: the 
development of the Saharan heat-low is regarded to be one essential component in this event. Ramel et al. (2006) have proposed that the meridional distribution of albedo over the Sahara desert controls the thermodynamics of the Saharan heat-low intensification around the time of onset. Saharan heat-low dynamics may play a part also in the intraseasonal variability of the West African monsoon circulation (Parker et al., 2005a).

Some understanding of the Saharan heat-low system has been obtained from heat-low studies in other parts of the world (e.g. Hoinka and Castro, 2003; Hoinka et al., 2007). Studies of the Australian deserts have shown that a continental-scale heat-low system is dominated by its diurnal cycle (May, 1995; Rácz and Smith, 1999). The heat-low is closely linked to continental thermal heating during the day, through divergence of mass from the atmospheric column causing a surface pressure minimum by hydrostatic balance; the minimum pressure occurs in the afternoon, with weak winds due to turbulent mixing in the CBL (Convective Boundary Layer). In the late afternoon the sensible heat flux decreases, leading to a significant fall in the boundary-layer turbulent mixing. The reduction in turbulent mixing allows the circulation to respond to the heat-low pressure gradient force; the winds then accelerate during the night. The behaviour of the low-level winds follows the typical evolution of a nocturnal jet (see Parker et al. (2005b) for discussion) with the Coriolis force causing a clockwise rotation of the wind vector overnight, and a maximum in the winds at around 0600 UTC (Lothon et al., 2008; Abdou et al., 2009). Studies over the Sahel (e.g. Dolman et al., 1997; Parker et al., 2005 b) confirm this basic daily sequence, with meridional advection dominating at night and convective turbulent processes controlling the dynamics by day. Above a heatlow, around and above the levels of significant diurnallyvarying boundary-layer heating, an anticyclone develops (Rácz and Smith, 1999). Spengler and Smith (2008) have shown that the anticyclone has a weaker diurnal cycle than the low-level heat-low vortex, and, at least in idealized model simulations, is close to gradient wind balance.

The lack of measurements over West Africa, and particularly over the Sahara, is a long-standing problem for the assessment of model-derived results and for the conceptual models constructed from them. Models are known to have significant errors over the Sahara and the Sahel, and in the consequent prediction of the West African monsoon (Haywood et al., 2005; Tompkins et al., 2005a) and the rest of the world (Rodwell and Jung, 2008). The possible reasons for such errors are many, including albedo errors, cloud parametrization, unresolved mesoscale dynamics, and dust aerosol processes.

The stronger night-time winds over the Sahara and its margins are very likely to be involved in dust and aerosol extraction (for instance this has been demonstrated for the Bodélé depression by Washington et al. (2006) and Knippertz (2008)), while daytime convection and convective cold pools may lead to dust uplift on large horizontal scales (Cakmur et al., 2004; Flamant et al., 2007; Bou Karam et al., 2008; Marsham et al., 2008a, 2008 b). Once elevated into the troposphere, the dust fields are able to influence the radiative budget over the Sahara, and, through advection, far from Africa.

The African Monsoon Multidisciplinary Analysis (AMMA) Special Observation Periods (SOPs) took place in 2006, and successfully collected a high density of measurements over West Africa (Redelsperger et al., 2006; Lebel et al., 2009). As part of the AMMA SOPs, Cuesta et al. (2008) have documented the 2006 seasonal variability of winds, thermodynamics and aerosol loadings over the Sahara, using measurements performed with a ground-based facility at Tamanrasset, complemented by data from satellite overpasses. Tamanrasset lies on the outskirts of the Saharan heat-low region, and is located close to mountains - see Figure 1. The present paper complements that of Cuesta et al. (2008) and focuses on the vertical structure of the Saharan atmospheric boundary layer in the core region of the Saharan heat-low. The paper makes use of observations acquired over wider regions of the Sahara by two airborne cross-sections through the Saharan heat-low, and satellite measurements, during 14 and 17 July. To the authors' knowledge, these airborne measurements give the first transects of the Saharan heat-low structures and the planetary boundary layer across the Sahara. A first assessment of the European Centre for Medium-Range Weather Forecasts (ECMWF) operational analyses for this region is presented also.

Section 2 deals with the processing of observed datasets for several instruments, and section 3 describes the synoptic environment of the West African monsoon and Saharan heat-low for the flight days of 14 and 17 July 2006. Section 4 gives details of the observed thermodynamics and the vertical structure of the boundary layer. Section 5 deals with comparison between ECMWF analyses and observations. Finally, section 6 concludes with a summary and discussion.

\section{Datasets and processing}

Measurements from two research flights are employed, each sampling one of the two peak times of the diurnal cycle (morning and mid-afternoon). An instrumented transfer flight operated by the Deutsches Zentrum für Luft- und Raumfahrt (DLR) occurred from 0710 to 0850 UTC on 14 July 2006, between Niamey and Agadir. Observations of the horizontal wind vector were obtained from the conical scanning airborne Doppler lidar (LIght Detection And Ranging) WIND (Wind INfrared Doppler lidar: Reitebuch et al., 2001, 2003; Drobinski et al., 2005b), which was installed on the DLR Falcon 20 aircraft. The backscattered signal from the atmosphere was generally high over the Sahara desert, due to the high aerosol loading of the atmosphere up to altitudes of 5-6 km, and the signal-to-noise ratio of the observations was very good throughout the whole altitude range. Thus a wind profile could be retrieved from line-ofsight measurements of only one scanner revolution, which results in a high horizontal density of the profiles. A wind vector profile with a vertical resolution of $250 \mathrm{~m}$ was obtained every $4 \mathrm{~km}$ along the flight track (Figure 1) 


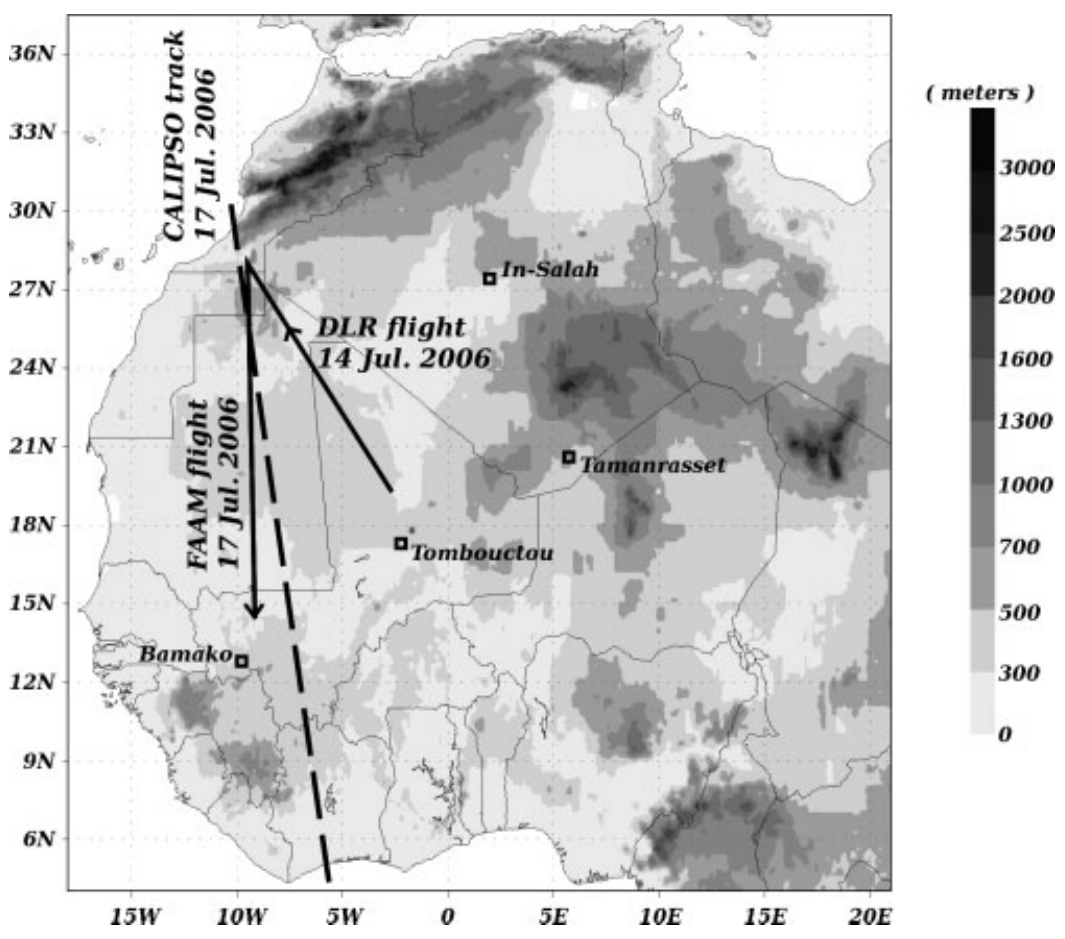

Figure 1. West African topography (m) with radiosonde station locations (squares), flight tracks (solid lines) and satellite CALIPSO ground track (dashed line).

from $18.95^{\circ} \mathrm{N}, 02.03^{\circ} \mathrm{W}(0710 \mathrm{UTC})$ up to $28.30^{\circ} \mathrm{N}$, $09.20^{\circ} \mathrm{W}$ (0850 UTC). The expected error of the retrieved wind velocity is rather constant with altitude, at about $1 \mathrm{~m} \mathrm{~s}^{-1}$. No significant systematic error occurs, except in the lowest range gate, which contains the ground surface return and is biased towards $0 \mathrm{~m} \mathrm{~s}^{-1}$, and in the worst case the first $250 \mathrm{~m}$ above the ground are contaminated. A relative or calibrated backscatter value was not derived from the WIND measurements, because the WIND instrument is optimized to measure wind velocity and not backscatter.

Another instrumented transfer flight, with the UK Facility for Airborne Atmospheric Measurements (FAAM) BAe146 aircraft, occurred on the afternoon of 17 July 2006 between Agadir and Bamako (Figure 1) (from 1350 UTC to 1607 UTC). The BAe146 was equipped with an Airborne Vertical Atmospheric Profiling System (AVAPS) dropsonde system: a curtain of 16 Vaisala RD93 dropsondes were released between $28^{\circ} \mathrm{N}, 9.2^{\circ} \mathrm{W}$ (1350 UTC) and $14^{\circ} \mathrm{N}, 8.1^{\circ} \mathrm{W}$ (1607 UTC) - see Table I. Note that transmission of all dropsonde data to the Global Telecommunication System was achieved in close to real time, with the first six sondes being transmitted by 1600 UTC for assimilation into numerical weather-prediction systems. The quality of the dropsonde data is generally excellent, although there is some loss of wind data at low levels (roughly from $825 \mathrm{hPa}$ down to the surface) for two dropsondes (at $21^{\circ} \mathrm{N}$ and $22^{\circ} \mathrm{N}$ ). This is thought to have been due to a problem with the parachutes. The dropsonde data have been linearly interpolated in the vertical, on to a $2 \mathrm{hPa}$ grid in pressure, following which temperature and humidity time-corrections have been made.
Complementary information about the vertical structure of dust layers over the Sahara is given by CALIPSO satellite data (operating since June 2006). The CALIPSO payload consists of the Cloud-Aerosol Lidar with Orthogonal Polarization (CALIOP), the Infrared Imaging Radiometer (IIR) and the Wide Field Camera (Winker et al., 2003, 2007). CALIPSO overpasses the Sahara twice a day, once during the daytime (between 1230 and 1430 UTC) and once during the night-time (between 0030 and 0230 UTC). Each overpass of the CALIPSO lidar provides a quasi-instantaneous view of the vertical structure of dust plumes and of the atmospheric boundary layer across the Sahara (i.e. between $15^{\circ} \mathrm{N}$ and $35^{\circ} \mathrm{N}$ in less than 5 minutes). In this study, the CALIOP attenuated backscatter profiles (level 1 operation data, version 2 are used) are inverted in order to avoid the ambiguities induced by atmospheric transmission. Such data processing is similar to the operational level 2 algorithm, which uses instead a first approximation of the multiple scattering coefficient equating 1 (see Winker et al., 2009). However, a specific processing is used for the case analysed in the present paper, given that the corresponding operational level 2 data (currently available) present numerous gaps. For this study, a standard backscatter lidar inversion technique (Fernald et al., 1972; Fernald, 1984) is implemented to compute the total backscatter profiles which are used as a proxy for describing the spatial distribution of dust concentration. This technique is not valid for dense clouds and below. It considers a normalization altitude with negligible content of particles (e.g. $10 \mathrm{~km}$ above mean sea level for the case in section 4). We use a particle backscatter-to-extinction 
Table I. Time (UTC) and location of the dropsonde releases during the 17 July FAAM flight, with estimated pressure of the top of the CBL (PC_BL, hPa).

\begin{tabular}{lcccc}
\hline Sonde & Lat. $^{\circ} \mathrm{N}$ & Lon. $^{\circ} \mathrm{W}$ & Time/UTC & PC_BL \\
\hline 1 & 28 & 9.19 & 1350 & 610.7 \\
2 & 26 & 9.01 & 1411 & 610.7 \\
3 & 24 & 8.84 & 1430 & 582.6 \\
4 & 23 & 8.76 & 1440 & 618.7 \\
5 & 22 & 8.67 & 1450 & 638.8 \\
6 & 20.9 & 8.59 & 1501 & 662.9 \\
7 & 20 & 8.51 & 1509 & 668.9 \\
8 & 19 & 8.44 & 1519 & 682.9 \\
9 & 18.5 & 8.4 & 1524 & 695 \\
10 & 18 & 8.35 & 1529 & 676.9 \\
11 & 17 & 8.28 & 1538 & 699 \\
12 & 16 & 8.2 & 1548 & 699 \\
13 & 15.8 & 8.19 & 1550 & 703 \\
14 & 15.4 & 8.16 & 1554 & 777.2 \\
15 & 15.2 & 8.14 & 1555 & 901.6 \\
16 & 14 & 8.1 & 1607 & 881.6 \\
\hline
\end{tabular}

Note that the upper level of the residual layer is not easy to define objectively, but based on the humidity and potential temperature profiles can be taken to be between 500 and $575 \mathrm{hPa}$ in all the profiles of Figure 4.

ratio of $0.024 \mathrm{sr}^{-1}$, representative of dust particles (Kaufman et al., 2003). This ratio is modulated in the vertical by a multiple scattering coefficient increasing exponentially from 0.65 at the layer top (around $5 \mathrm{~km}$ above mean sea level for the case in section 4), 0.87 below $500 \mathrm{~m}$ and at the ground 0.95 , in agreement with the MonteCarlo simulations of Young et al. (2008). The CALIOP data were processed with a $60 \mathrm{~m}$ resolution in the vertical and $12 \mathrm{~km}$ resolution in the horizontal, and then noise was reduced by a sliding average over a window of eight points in the vertical and two in the horizontal. Qualitative tracking of dust plumes over the Sahara has been carried out using observations from the Spinning Enhanced Visible and Infrared Imager (SEVIRI) - with a 15-minute temporal resolution - onboard MSG (Meteosat Second Generation) via false colour images available from http://loaamma.univ-lille1.fr/AMMA/.

Radiosondes from the Tamanrasset station $\left(22.79^{\circ} \mathrm{N}\right.$, $5.42^{\circ} \mathrm{E}$ ) provide a longer-term complement to the aircraft and satellite data. During the AMMA-SOP campaign, the normal sampling frequency of two per day (at 0000 and 1200 UTC) was increased by the addition of 0600 and 1800 UTC soundings from 1 June to 15 September 2006 , to provide a better coverage of the diurnal cycle (Parker et al., 2008). Daily soundings from the station at In Salah at 1200 UTC are used also in this study because of its location, remote from orography (Tamanrasset can be subject to topographic effects of the nearby Hoggar mountains, which may, for example, generate boundary-layer separation effects, as discussed by Cuesta et al. (2009)).

ECMWF model analyses at 0600, 1200 and 1800 UTC have been used to characterize the synoptic situation on the study days of 14 and 17 July 2006. In order to perform a direct ECMWF analyses and observations comparison, it is necessary to match the time of the observations and ECMWF analysis as closely as possible. Consequently the ECMWF $4 \mathrm{~V}$ analysis ${ }^{\dagger}$ (available every three hours) has been used.

Comparisons with dropsonde data have been performed by interpolating the analysis to the locations of the dropsondes. It is worth noting that 15 out of the 16 dropsondes were assimilated into the model analysis, albeit at a lower vertical resolution than the original data. The vertical resolution of the observations that reached the Global Telecommunication System and were available to the $4 \mathrm{~V}$ assimilation system was particularly low near the surface. There were few or no observations within the moist boundary layer in the southern part of the flight transect and few observations below $700 \mathrm{hPa}$ in the dry area around $20^{\circ} \mathrm{N}$.

The DLR Falcon and FAAM flight tracks are presented in Figure 1, as well as the location of radiosonde stations, ground CALIPSO tracks and topography. Locations and times of dropsonde releases are presented in Table I.

\section{Synoptic conditions and seasonal background to the study period}

The large-scale context of the 2006 monsoon onset period has been described by Janicot and Sultan (2007) and Janicot et al. (2008). The 2006 summer was a near-normal season in terms of convective activity, but a delayed onset occurred, possibly due to a Madden-Julian Oscillation event. The onset date recorded in 2006 was 10 July (Janicot et al., 2008), while the first significant Mesoscale

\footnotetext{
The $4 \mathrm{~V}$ analysis is the final nonlinear trajectory that provides an optimal fit to the observations and the background field over the $12 \mathrm{~h}$ interval.
} 
Convective System (MCS) passed over Niamey on 14 July. Therefore, the 14 and 17 July flights were performed during the first days after monsoon onset had occurred, and the northwards shift of the Saharan heat-low to its summer location was complete (e.g. Ramel et al., 2006).

Figure 2 presents the ECMWF analyses for the Saharan heat-low location and wind vectors at $925 \mathrm{hPa}$, at 0600 and 1200 UTC on 14 July (Figure 2(a)-(b), spanning the duration of the flight) and at 1200 UTC and 1800 UTC on 17 July (Figure 2(c)-(d), spanning the flight). The Saharan heat-low is centred over Mauritania during the early morning of 14 July, while it is located further to the east over Mali during the afternoon of 17 July The circulation around the Saharan heat-low centre is at its most intense over West Africa at low levels, with the maximum horizontal velocity $\left(>16 \mathrm{~m} . \mathrm{s}^{-1}\right)$ in the southeastern part on 14 July (in contrast to the maximum velocities lying in the northwestern part on 17 July). The difference between the wind fields on the two days can be associated to some extent with the diurnal cycle of the Saharan heat-low. During the 14 July flight, a morning weakening of the Saharan heat-low occurred, while an early evening (1800 UTC - Figure 2(d)) deepening of the Saharan heat-low occurred on 17 July, with the winds beginning to accelerate, in agreement with the Rácz and Smith (1999) model and the analyses of Parker et al. (2005a).

At low levels over West Africa, the penetration of cool, humid southwesterly monsoon winds towards the north is bounded by the intertropical front (ITF), which lies some

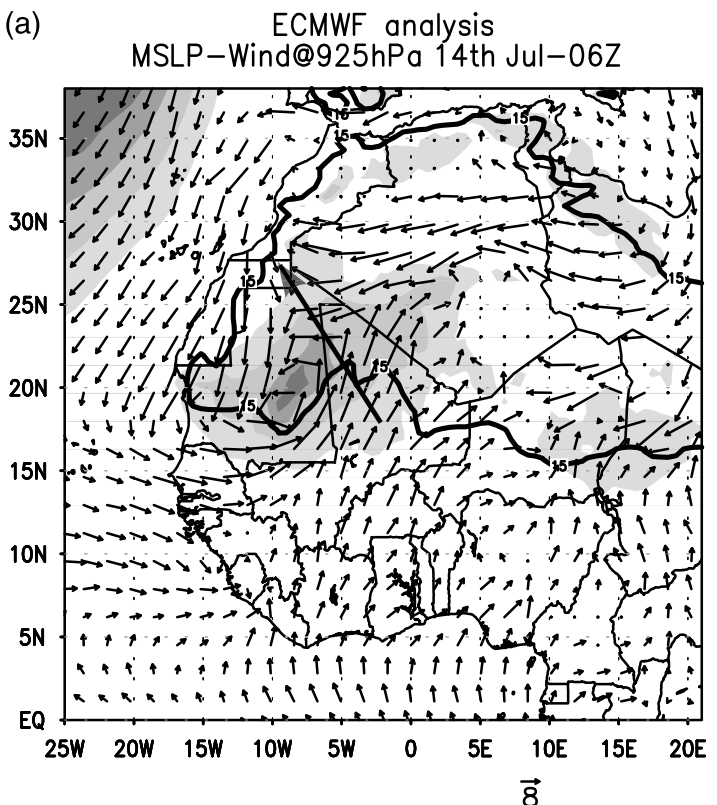

(c)

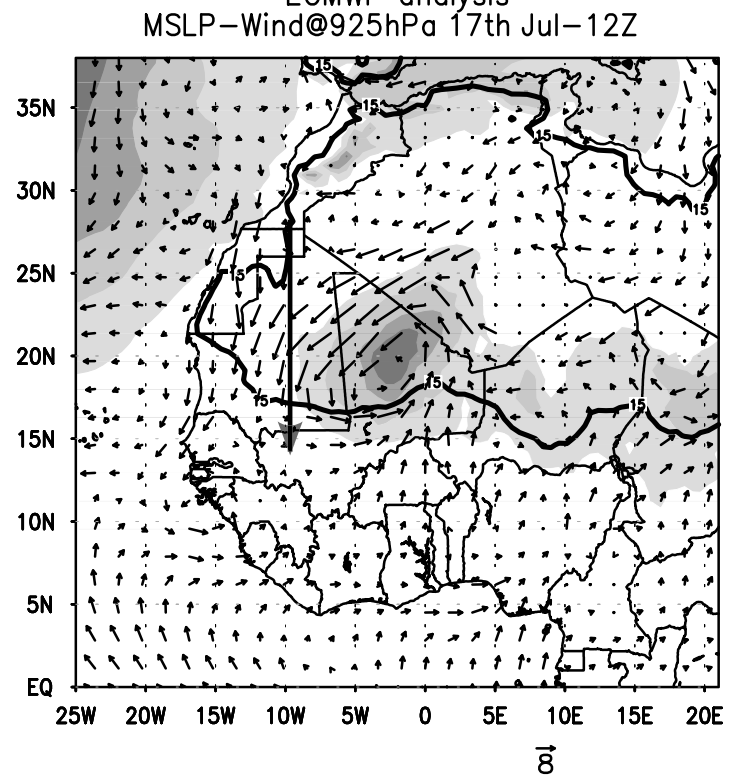

(b) ECMWF analysis

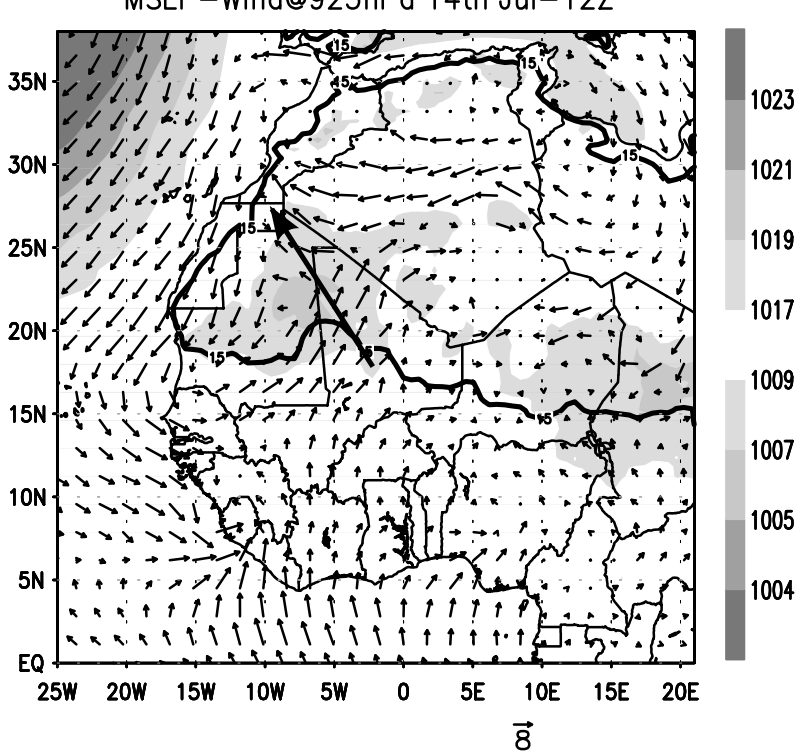

(d)

ECMWF analysis

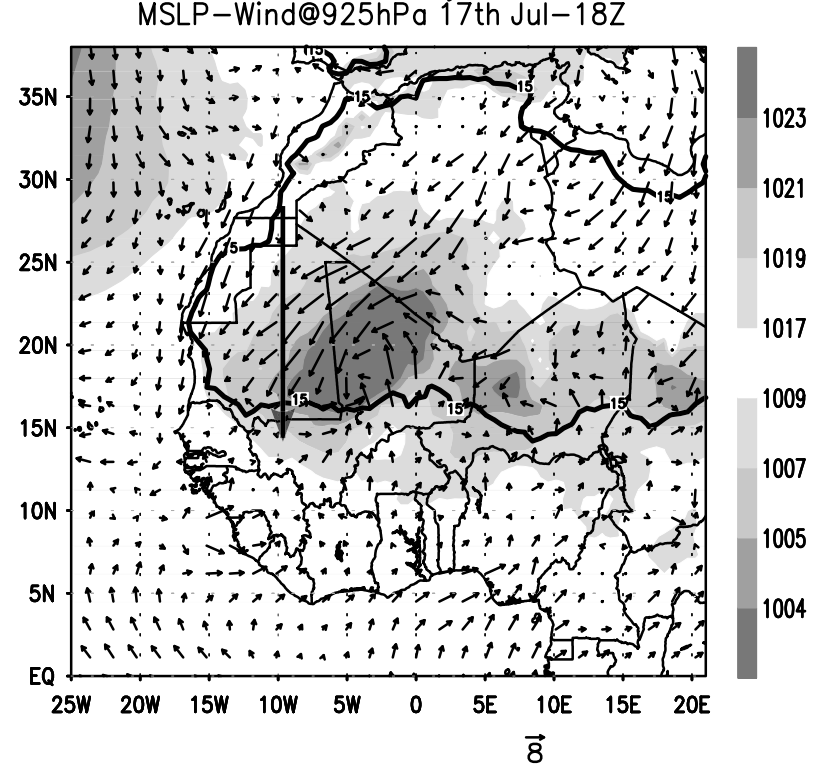

Figure 2. ECMWF analyses. Mean-sea-level pressure (hPa, shaded), wind vectors at $925 \mathrm{hPa}$ and $15^{\circ} \mathrm{C}$ dew-point isotherm at $2 \mathrm{~m}$ height (solid black line) for (a) 14 July 2006 at 0600 UTC, (b) 14 July at 1200 UTC, (c) 17 July at 1200 UTC, (d) 17 July at 1800 UTC. North-westwards arrow is the DLR flight track (14 July) and the southwards arrow is the FAAM flight track (17 July). 
5 degrees north of the ITCZ and separates the monsoon flow from the warm and dry north-easterly Harmattan winds characteristic of the southern Sahara (Hamilton et al., 1945). The direct connection between the southern part of the Saharan heat-low vortex and the northward continental penetration of the south-westerly monsoon flow (e.g. around $16^{\circ} \mathrm{N}, 5^{\circ} \mathrm{W}$ in Figure 2(a)) gives, for these two days, an illustration of the influence of the Saharan heat-low intensity and location on the moisture budget and the transport from the Gulf of Guinea to the continent (as in Ramel et al., 2006).

For objective identification of the ITF, Eldridge (1957) recommended the use of a contour of dew-point, $T_{\mathrm{d}}=$ $15^{\circ} \mathrm{C}$, and noted that strong humidity gradients make this measure relatively insensitive to the absolute choice of $T_{\mathrm{d}}$. The $15^{\circ} \mathrm{C}$ (Figure 2) dew-point isotherm shows that the northward penetration of the ITF is closely related to the southerly Saharan heat-low winds. Since these winds are more intense on 14 July at 0600 UTC than 17 July at 1200 UTC, the southwesterly monsoon flow is more intense and penetrates further north on 14 July.

\section{Thermodynamic and kinematic structures observed on 14 and 17 July 2006}

Figure 2(a)-(b) shows that the 14 July flight cut through the northeastern tip of the Saharan heat-low and captured the westerly monsoon flow originating from the Gulf of Guinea and the western coast of Africa (around Dakar). The northern part of the flight captured the flow from eastern Algeria and Tunisia. At mid-levels, an African Easterly Wave trough was located over the cyclonic vortex associated with the Saharan heat-low (not shown). The same trough axis over the Saharan heat-low vortex can be seen during the 17 July flight, which captured mainly the north-easterly flow on the western flank of the heat-low (Figure 2(c)-(d)).

\subsection{July 2006}

Figure 3(a) and (c) presents the meridional and zonal winds from the airborne Doppler lidar WIND on the 14 July flight. As noted in section 2, the 14 July flight took place in the early morning when the CBL was shallow. Therefore this flight sampled the evolution of a deep residual layer which is a unique atmospheric feature in the global climate.

The 14 July flight crossed the Saharan heat-low from southeast to northwest in its core eastern part (see Figure 2(a)-(b)). The observed ITF can be identified as the region at $22.2^{\circ} \mathrm{N}(0745$ UTC) where there was a sharp transition between the southwesterly monsoon and the northeasterly Harmattan (Figure 3(a) and (c)): the discrepancy between this transition in winds and the thermodynamic ITF can be surmised in Figure 2(a)-(b). However, there was a form of double front (at $21^{\circ} \mathrm{N}$ and $22.2^{\circ} \mathrm{N}$ ) in the observed meridional and zonal winds: the northernmost of these was shallower and had a weaker component of westerly winds. Above the monsoon layer, the African Easterly Jet was present at around $5500 \mathrm{~m}$ altitude, and easterly wind shear below this height persisted to around $23.5^{\circ} \mathrm{N}$ (Figure 3(c)).

After crossing the ITF, the aircraft flew above the Saharan heat-low core (Figure 2), and sampled the northeasterly Harmattan winds below 2000 m, with a maximum in the northerly component around $23^{\circ} \mathrm{N}$ at $1000 \mathrm{~m}$ (Figure 3(a)). At mid-levels a distinct shear line was located over the cyclonic Saharan heat-low vortex, shown by a dashed line in Figure 3(a) and (c) separating the northeasterly flow ('Nw1/Nw2') from southeasterly flow at 5000-6000 m ('Sw2') and from southwesterly flow at $3000 \mathrm{~m}$ ('Sw1').

The magnitude of the winds in the southeastern part of the Saharan heat-low seems to have been responsible for a deep northward penetration of the low-level monsoon winds during the early morning of 14 July 2006, and it was concomitant with the influence of an MCS, generating a northward-moving gravity current and thereby enhancing the monsoon southerlies. Indeed, overnight on 13-14 July, a line of MCSs developed across southwestern and northeastern Mali, with the northeastern MCS remaining around $2^{\circ} \mathrm{W}-3^{\circ} \mathrm{W}, 17^{\circ} \mathrm{N}-18^{\circ} \mathrm{N}$ between 1700 and 2300 UTC on 13 July, producing a strong downdraught and cold pool (not shown). Flamant et al. (2007), Bou Karam et al. (2008) and Marsham et al. (2008b) describe evidence of similar cold pools reinforcing the monsoon and ITF during the pre-onset of the 2006 and 2007 monsoon seasons.

\subsection{July 2006}

The dropsondes deployed on 17 July (see Table I) provide nearly simultaneous observations of the thermodynamic fields at a spatial resolution of 1 degree of latitude and better. The profiles allow a study of the atmospheric vertical structure from north to south across the Sahara, including the Saharan heat-low, ITF and West African monsoon, with a focus on the boundary layer.

Figure 4 presents the potential temperature $(\theta)$ and mixing ratio profiles deduced from the 16 dropsondes released on 17 July. All of the 'Saharan' sondes north of the ITF, between $16^{\circ} \mathrm{N}$ and $28^{\circ} \mathrm{N}$, show an adiabatic layer from the surface up to around $700-650 \mathrm{hPa}$. This adiabatic layer is very well marked and corresponds to the well-mixed convective boundary layer. Above this wellmixed layer the profile is close to adiabatic, but slightly stable up to around $525-570 \mathrm{hPa}$, suggesting the presence of a residual boundary layer aloft. Such a boundary layer structure (with two vertical layers) has previously been noted by Parker et al. (2005a), Flamant et al. (2007) and Cuesta et al. (2009). We will refer to the lower wellmixed region as the Convective Boundary Layer (CBL), though Flamant et al. (2007) described this layer as the 'internal boundary layer'.

South of the ITF, at the southern end of the dropsonde section $\left(14^{\circ} \mathrm{N}\right)$, Figure 4 shows evidence of the monsoon flow, with the $\theta$ and mixing ratio profiles indicating the mixed-layer top located around $900 \mathrm{hPa}$, and decreasing in depth at $15.2^{\circ} \mathrm{N}$. For the southernmost dropsondes 

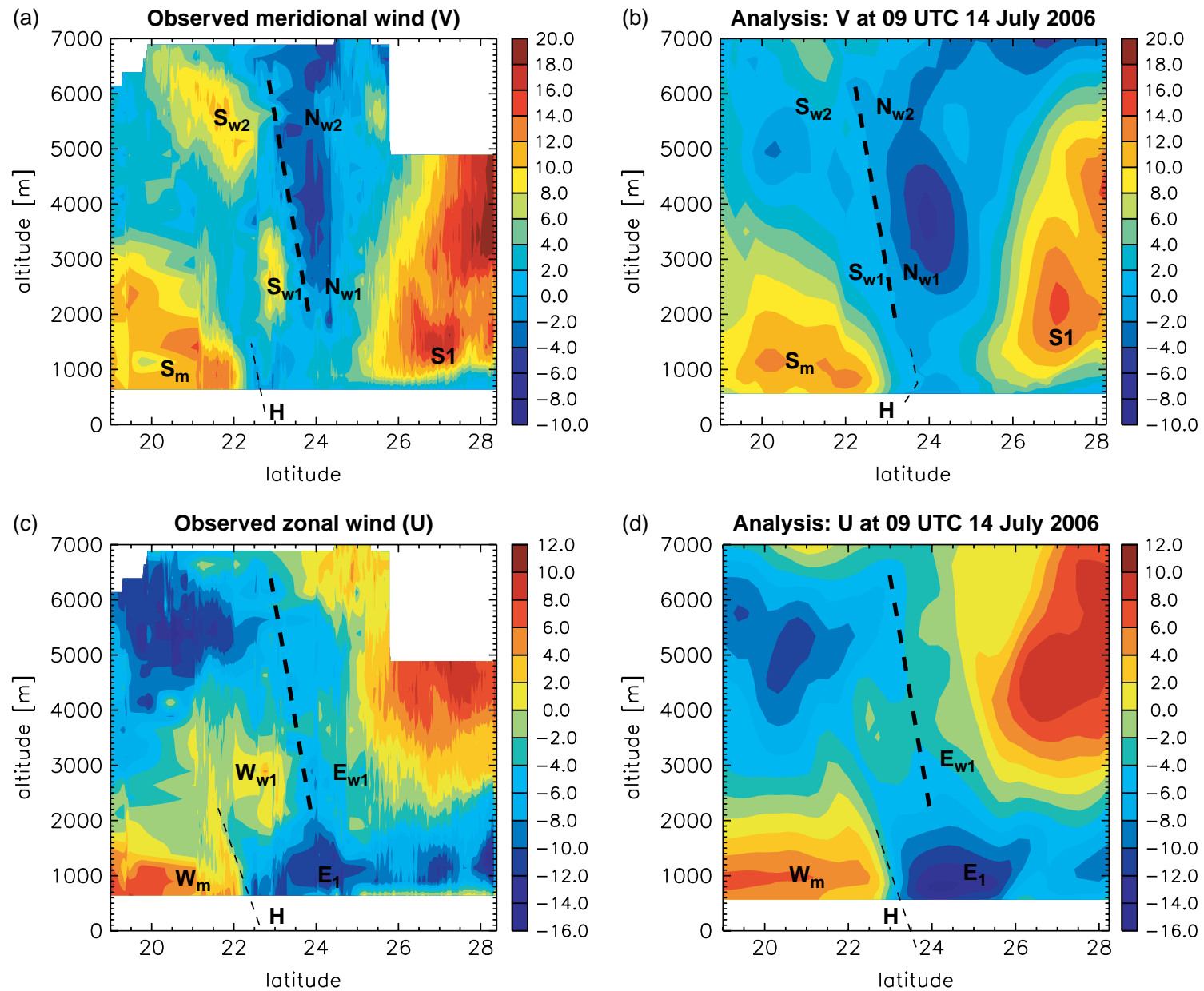

Figure 3. Meridional (a),(b) and zonal (c),(d) wind components ( $\mathrm{m} \mathrm{s}^{-1}$ ) from the airborne Doppler lidar WIND (a),(c) and ECMWF analysis at 0900 UTC (b),(d), for the DLR flight of 14 July 2006. The bold dashed line marks the trough line, which separates southwesterly from northeasterly winds at $3000 \mathrm{~m}$ altitude. The fine dashed lines mark the locations where each wind component changes sign at low levels. These are used to locate the axis of the heat-low vortex $\mathrm{H}$.

$\left(14^{\circ} \mathrm{N}, 15.2^{\circ} \mathrm{N}, 15.5^{\circ} \mathrm{N}\right)$, the rapid increase in $\theta$ above the $\mathrm{CBL}$ (reaching the value of $\sim 318 \mathrm{~K}$ ) and the rapid decrease of mixing ratio (down to around $5 \mathrm{~g} / \mathrm{kg}$ ) reveals the presence of the Saharan Air Layer passing above the monsoon layer (see also Parker et al., 2005a).

In addition to the dropsonde data, the daytime CALIPSO transect for 17 July (Figure 5(a)) shows several aerosol layers within the Saharan atmospheric boundary layer. From $\sim 16^{\circ} \mathrm{N}$ to $\sim 26^{\circ} \mathrm{N}$, an elevated dust layer, which is mainly located between the $318 \mathrm{~K}$ and $321 \mathrm{~K}$ isentropes, lies within the upper levels of the slightly stratified residual layer over the Sahara. Underneath this layer, from $\sim 22^{\circ} \mathrm{N}$ to $\sim 27^{\circ} \mathrm{N}$, mixing within a CBL from the surface and up to the $318 \mathrm{~K}$ isentrope $(\sim 4.2 \mathrm{~km}$ above mean sea level) is indicated by nearly constant profiles of moderate aerosol backscatter coefficient (approximately 2 to $2.7 \mathrm{~km}^{-1} \mathrm{sr}^{-1}$ ). From $19^{\circ} \mathrm{N}$ to $22^{\circ} \mathrm{N}$, the CBL is separated from the layer of high dust within the residual layer by an intermediate layer with lower dust concentration (suggested by backscatter coefficient $\sim 1.5 \mathrm{~km}^{-1} \mathrm{sr}^{-1}$ ) at around 3-4 km altitude. In the dropsonde profiles of Figure 4, this layer of low dust concentration is coincident with low humidity mixing ratios in the lower part of the residual layer, between 650 and $700 \mathrm{hPa}$. Therefore, from $19^{\circ} \mathrm{N}$ to $22^{\circ} \mathrm{N}$, there is consistent evidence in both the dropsonde and the CALIPSO data of stratification within the residual layer.

South of $22^{\circ} \mathrm{N}$, as far as the ITF region $\left(15.5^{\circ} \mathrm{N}\right)$, the dense dust layer extending from the surface up to $2.5 \mathrm{~km}$ (with backscatter coefficient $>5 \mathrm{~km}^{-1} \mathrm{sr}^{-1}$ ) corresponds to a CBL containing a dust plume that originated earlier in the morning in central Mauritania (the movement of the plume is apparent in a complete time-sequence of SEVIRI images (not shown) and the origins over Mauritania are consistent with strong northwesterly $10 \mathrm{~m}$ winds, seen in Figure 5(b)). At the time of the CALIPSO transect, this plume was being advected toward the southwest, while other plumes were located to the east (see Figure 5(c)). South of the ITF $\left(\sim 15^{\circ} \mathrm{N}\right)$ and up to $\sim 1.5 \mathrm{~km}$ above mean sea level, the monsoon flow is depicted in the CALIPSO data (Figure 5(a)) by a dust plume at its front, as previously observed (Flamant et al., 2007; Bou Karam et al., 2008; Marsham et al., 2008b) and some sparse clouds at the top of the Saharan boundary layer (around $6 \mathrm{~km}$ altitude, $\left.14^{\circ} \mathrm{N}\right)$.

These data have confirmed that on this transect through the western flank of the Saharan heat-low, the two-layer division of the Saharan atmospheric boundary layer into 

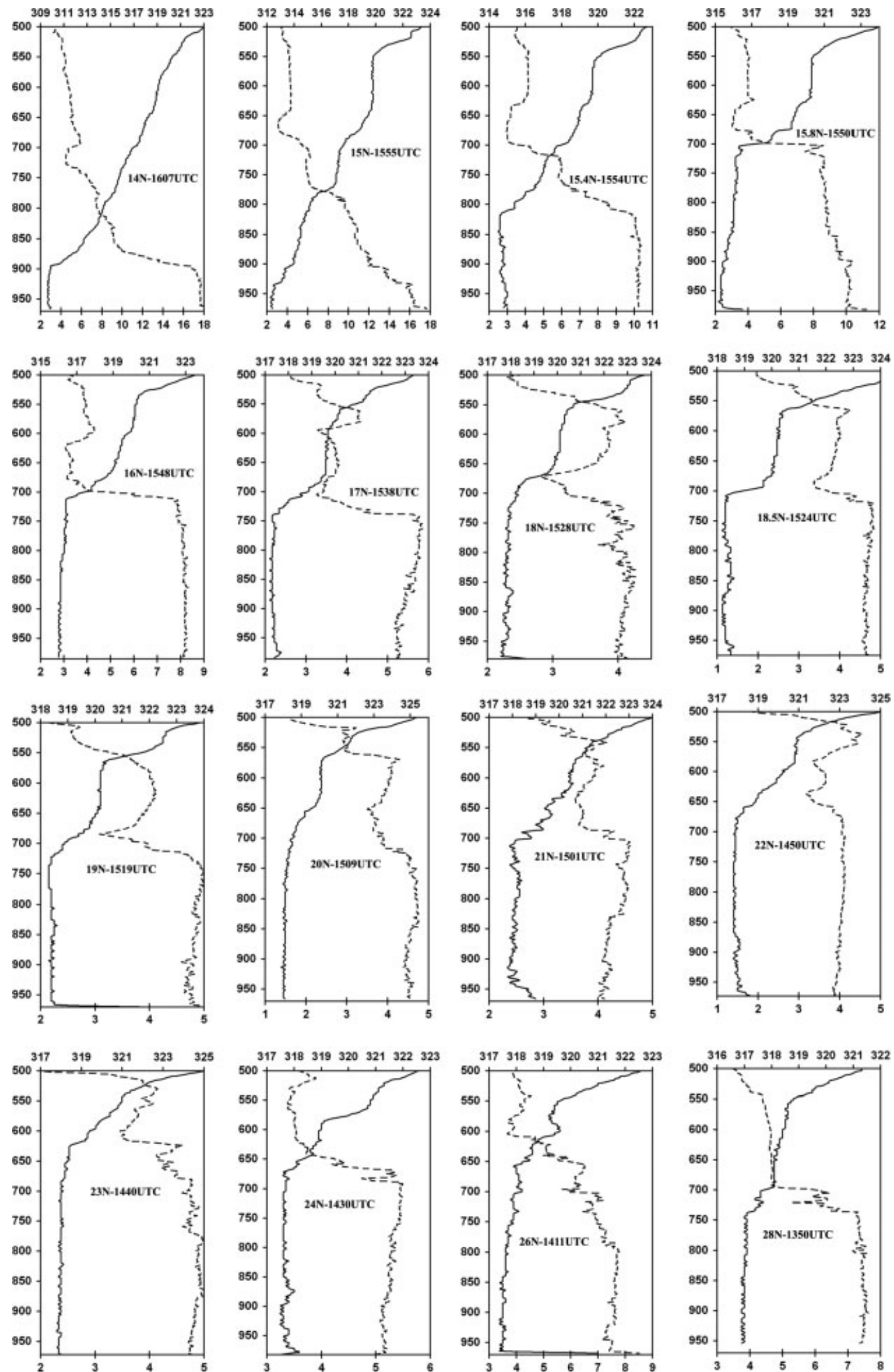

Figure 4. Potential temperature and humidity mixing ratio for all dropsondes released on 17 July 2006. The south to north sequence of dropsondes is presented from left to right and top to bottom; location and time is indicated for each plot. Horizontal upper scale is for potential temperature (solid line, $\mathrm{K}$ ), lower scale is for humidity mixing ratio (dashed line, $\mathrm{g} \mathrm{kg}^{-1}$ ).

a CBL and residual layer, noted previously by Parker et al. (2005a) and Flamant et al. (2007), spanned the Sahara from the north to south in mid-afternoon. The Tamanrasset radiosoundings of 17 July (Figure 6(a)) exhibit the existence of a two-layer profile also with an internal CBL below the residual layer, at 1200 and 1800 UTC (but less marked), suggesting that this division is a mode of the atmospheric state over the Sahara which can persist throughout the day. Likewise, in the northern part of the Sahara at In Salah (Figure 6(b)), 


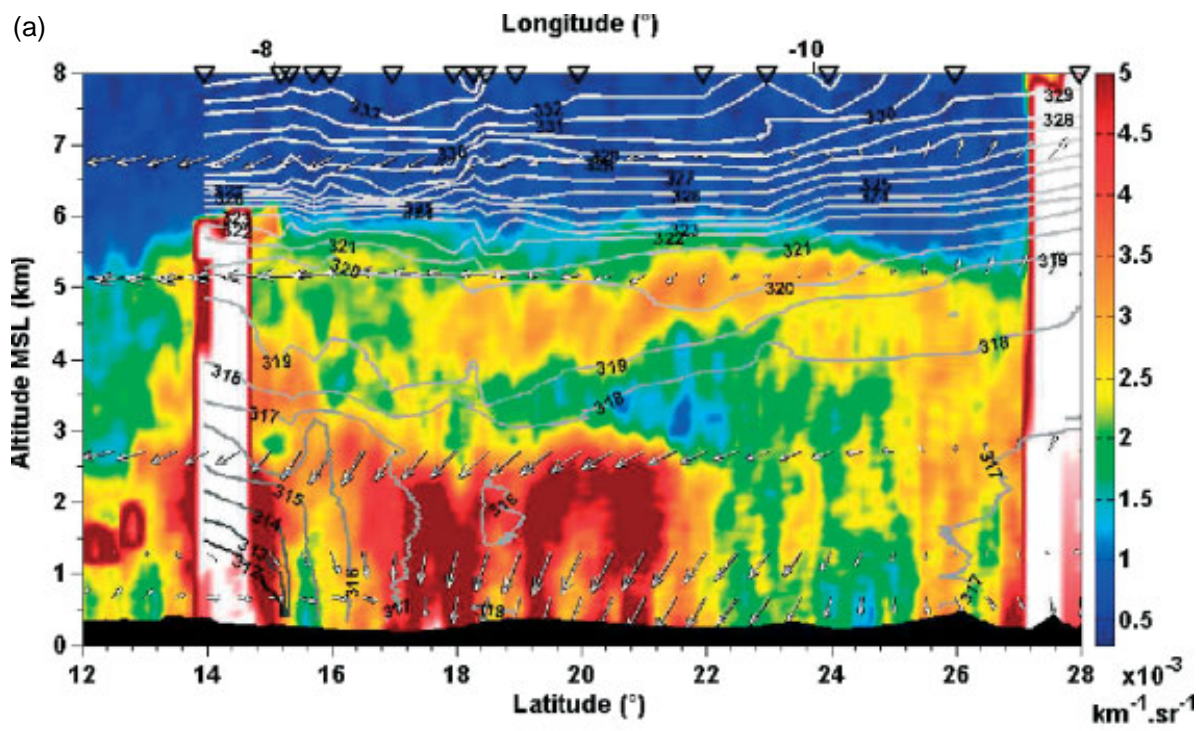

(b)

(c)
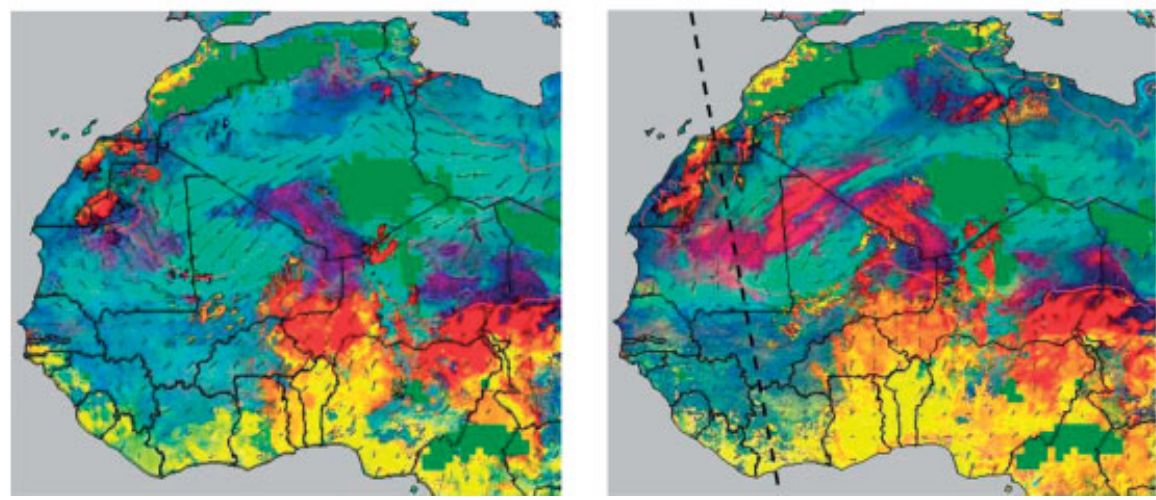

Figure 5. (a) CALIPSO track of backscatter profiles at $532 \mathrm{~nm}$ over West Africa on 17 July at 1406 UTC (see section 2). White colour corresponds to dense clouds and masking underneath. The outline of the topography appears in black. Superimposed on CALIPSO lidar data are: ECMWF analysis horizontal wind fields at 1200 UTC interpolated at the transect location and contours of potential temperature derived from the dropsondes (locations indicated by black triangles on top horizontal axis). SEVIRI-derived false-colour images of West Africa on 17 July are shown (b) at 0830 UTC and (c) 1400 UTC. Aerosols, clouds and land surface are identified by the purple/red, orange and green colours, respectively. The dashed line indicates the CALIPSO track. ECMWF analysis horizontal winds at $10 \mathrm{~m}$ and the $15^{\circ} \mathrm{C}$ dew-point line (indicator of the ITF) are superimposed (analysis at 0600 UTC for (b) and 1200 UTC for (c)).

the only daily sounding (at 1200 UTC) exhibited two near-adiabatic layers (from ground to $650 \mathrm{hPa}$ and 600 to $500 \mathrm{hPa}$ ) at $1200 \mathrm{UTC}$, with a deep CBL showing that the residual layer above was nearly consumed by the mixing from below at this time. It is important to note that this structure was not observed at Tamanrasset on 14 July, when a nearly well-mixed and adiabatic boundary layer was present at 1200 UTC and 1800 UTC (not shown). Cuesta et al. (2008) have observed the Saharan atmospheric boundary layer to be well-mixed, with no residual layer, from early afternoon onwards in a case from 25 June 2006. Inspection of all of the 0600, 1200 and 1800 UTC Tamanrasset radiosondes from July 2006 has shown that the situation of a CBL overlain by a nearadiabatic residual layer is not a marginal event, because the existence of a residual layer can be inferred at 1200 UTC for 1, 5, 8, 9, 16, 17, 23 and 26 July 2006, and on some of these days, the residual layer persists to 1800 UTC. It should be recalled that Tamanrasset is located in a region of significant orography (the Hoggar) and therefore the Tamanrasset profiles can be influenced by orographic circulations. The In Salah radiosoundings also exhibit some records during July 2006 with a split boundary layer, showing a residual layer at 1200 UTC on 12, 13, 14, 15, 21 and 30 July.

The dropsonde and radiosonde observations also show that the daytime Saharan atmospheric boundary layer seems commonly to be characterized by a division between a residual layer aloft and a growing CBL driven by heating from the surface (Figure 4). This model for the growth of a convective boundary layer is a standard 'textbook' concept (e.g. Oke, 1988). However, over the Sahara the phenomenon exhibits two remarkable aspects. First, the extreme depth of the Saharan atmospheric boundary layer, up to around $600 \mathrm{hPa}$ or even $500 \mathrm{hPa}$, means that it encompasses over $40 \%$ of the mass of the atmospheric column. This deep boundary layer can carry a significant mineral dust loading, whose transport is of global importance (Dunion and Velden, 2004). In turn, transport of dust will be controlled by the mixing processes which result from the boundary layer response to the surface. Second, it was shown that the 

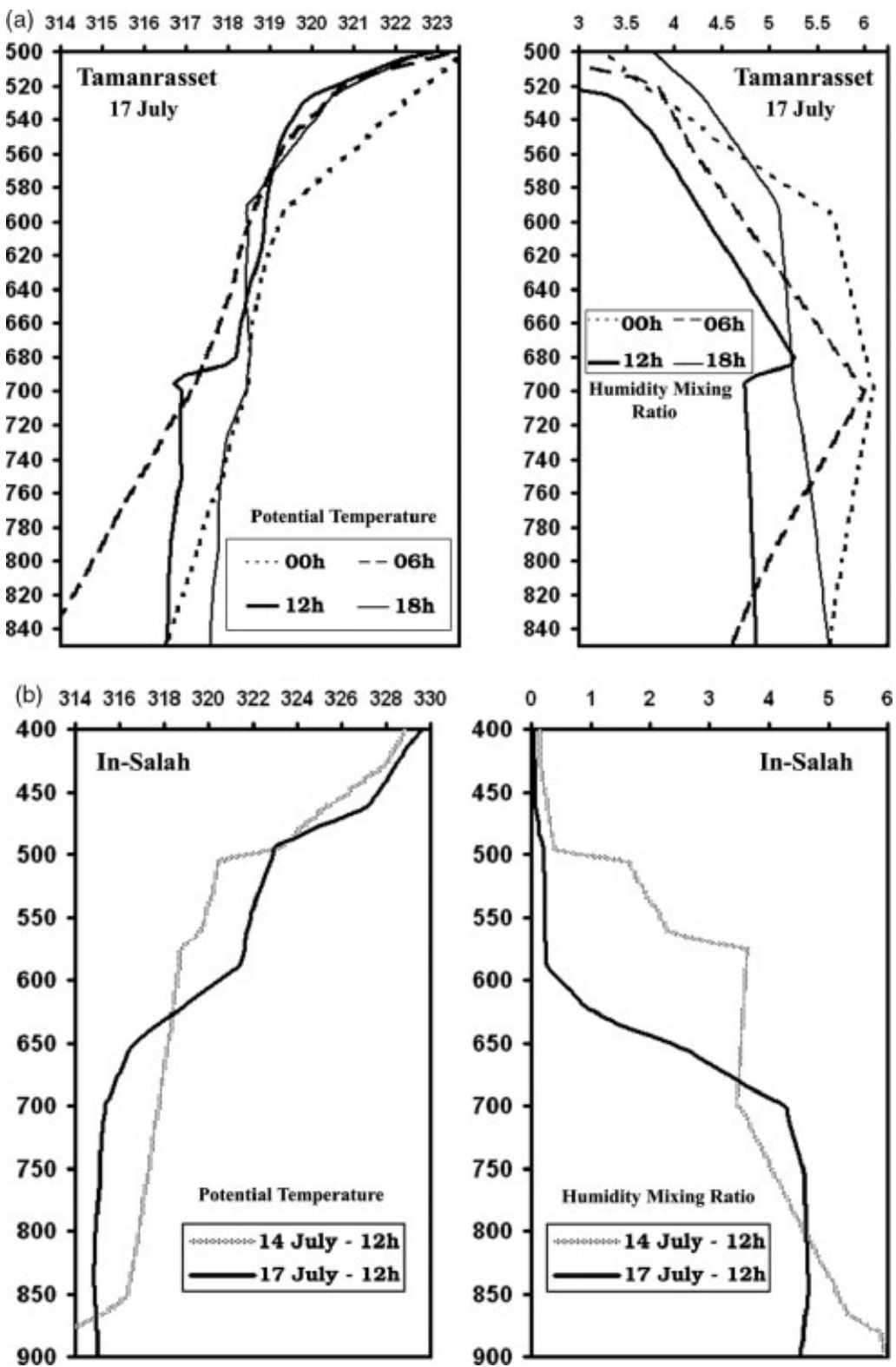

Figure 6. Potential temperature (left) and humidity mixing ratio (right) measured at Tamanrasset on 17 July 2006 (a) and In Salah on 14 and 17 July 2006 (b). For Tamanrasset, the dotted curve is the 0000 UTC sounding, dashed curve is the 0600 UTC sounding, solid bold curve is the 1200 UTC sounding and solid thin curve is the 1800 UTC sounding.

residual layer can persist throughout the day on some days in the summer (for instance in the Tamanrasset radiosondes of Figure 6(a)), with coherence observed over many hundreds of kilometres in the afternoon dropsondes. Therefore, there is enormous benefit in further exploring the diurnal evolution of the Saharan atmospheric boundary layer in order to better understand and predict the dynamics and mixing in this part of the global climate system.

\section{Thermodynamics and winds in ECMWF analyses compared with observations}

\subsection{July 2006}

Figure 3(b) and (d) presents the winds in the ECMWF analysis (see section 2) at 0900 UTC, for comparison with Figure 3(a) and (c) discussed in section 4.1. Detailed study of the various flows represented in the analysis shows that the main observed features are captured, even though the WIND lidar observations were not assimilated in this analysis.

On the basis of the meridional wind convergence, the ITF in the analysis is located further north, at $23^{\circ} \mathrm{N}$ (Figure 3(b) and (d)), and the monsoon layer to the southeast of the ITF produces a double maximum core of winds, centred at $20.5^{\circ} \mathrm{N}$ and $22^{\circ} \mathrm{N}$ (Figure $3(\mathrm{~b})$ ). As noted in section 4.1, it is possible that, on this day, the ITF was reinforced by cold pool flows emanating from convective storms further south, which may have increased its northward penetration. The maximum of the Harmattan winds in the ECMWF analysis is shifted slightly, to $23.5^{\circ} \mathrm{N}$ (Figure 3(c)-(d)), relative to observations. The mid-level 
shear line appears in the analysis, around 0.5 degrees to the southeast of the observed position (Figure 3(b) and (d)), but the strength of the southerly component of the winds to the southeast of the shear line is underestimated in the model analysis with a southerly component of less than $2 \mathrm{~m} . \mathrm{s}^{-1}$, compared with between $8 \mathrm{~m} . \mathrm{s}^{-1}$ and $12 \mathrm{~m} . \mathrm{s}^{-1}$ in the observations. At $3000 \mathrm{~m}$ the westerly component of the winds to the southeast of the shear line is not represented in the analysis, which has an easterly component throughout this region. At 5000-6000 m the easterly component of the analysis winds is similar to the observed.

\subsection{July 2006}

The array of dropsonde data along the flight, and the corresponding ECMWF analysis fields, are displayed in Figure 7. Estimated CBL height with observations is also given in Figure 7 and Table I; the method of computing CBL depth is to lift a parcel from a level just above the surface layer (10 $\mathrm{hPa}$ above the surface), then choose the level at which the parcel is negatively buoyant relative to the environment. From trial and error we use a threshold of $0.7 \mathrm{~K}$; if the parcel is more than $0.7 \mathrm{~K}$ colder than its environment then we have reached the top of the CBL. The CBL extends roughly to $900 \mathrm{hPa}$ in the monsoon flow and expands to $700 \mathrm{hPa}$ from $15^{\circ} \mathrm{N}$ to $16^{\circ} \mathrm{N}$ in a particularly sharp rise at the ITF.

In the observations, the region of maximum $\theta$ in the $\mathrm{CBL}$ is located around $19^{\circ} \mathrm{N}$ (Figure $7(\mathrm{a})$ ), whereas in the analysis the maximum is around $20^{\circ} \mathrm{N}$ (Figure $7(\mathrm{~b})$ ). The region of maximum $\theta$ is broader also in the analysis, so the region between $20^{\circ} \mathrm{N}$ and $24^{\circ} \mathrm{N}$ is warmer by $\sim 0.5 \mathrm{~K}$ in the analysis than observations. At these latitudes, the 'analysis increments' are acting to cool the analysis by approximately $1 \mathrm{~K}$ below $700 \mathrm{hPa}$ with respect to the model first guess. Note that the dropsonde data below $700 \mathrm{hPa}$ at $20^{\circ} \mathrm{N}$ were not available to the assimilation system.

The ITF is located between $15^{\circ} \mathrm{N}$ and $16^{\circ} \mathrm{N}$ in the observations (Figure 4 and Figure $7(\mathrm{a})$ ). In the analysis (Figure 7(b)) this gradient is shifted northward by around 1 degree, and, as a consequence, the region between $15.5^{\circ} \mathrm{N}$ and $17^{\circ} \mathrm{N}$ is too cool. On the northern side of the Sahara, the analysis is cooler also at $28^{\circ} \mathrm{N}$ by $1 \mathrm{~K}$, with a similar penetration of cool air too far (southward) into the desert.

The analysis has warmer temperatures than the two southernmost dropsondes, in the monsoon layer close to the surface. In fact, the differences between the dropsonde observations and the analysis are larger than the differences between observations and the short-range forecast used as background or first guess in the analysis. This implies that the analysis increments (analyses minus short-range forecast) have warmed the analysis by $0.2 \mathrm{~K}$ to $1.2 \mathrm{~K}$ at around $900 \mathrm{hPa}$ with respect to the first guess, when they should actually be cooling the analysis in order to reduce the difference between observations and analyses. On the other hand, above the observed boundary layer the model first guess is too cold and there the analysis increments are warming to reduce the difference between analysis and observations. Thus, even if all the observations are used in the analysis it is not always the case that they will all have a strong influence on the analysis, e.g. the observations at $900 \mathrm{hPa}$ in this case. This can occur particularly when other nearby observations pull the analysis in the opposite direction, e.g. observations above the boundary layer in this case.

Equivalent potential temperature $\left(\theta_{\mathrm{e}}\right)$ fields highlight the spatial coherence of the CBL and residual layer across the transect (Figure 7(c)). The CBL is well mixed in $\theta_{\mathrm{e}}$, with the contours oriented vertically, while the residual layer shows horizontal layering of $\theta_{\mathrm{e}}$ contours. In the Saharan CBL between $19^{\circ} \mathrm{N}$ and $24^{\circ} \mathrm{N}, \theta_{\mathrm{e}}$ is lower in the analysis than in the observations (Figure 7(c)-(d)), and given the warmer temperatures in the analysis, this anomaly is due to the lower humidity mixing ratio in the analysis for that region. Between $15.5^{\circ} \mathrm{N}$ and $17^{\circ} \mathrm{N}$ the cool temperatures in the analysis are accompanied by high $\theta_{\mathrm{e}}$ values relative to the observations, consistent with the model advecting the monsoonal air too far north. $\theta_{\mathrm{e}}$ in the monsoon layer is lower in the analysis than observations and has two peaks (Figure 7(d)), which are also not observed (Figure 7(c)). Consistent with this, the moist layer observed in the two southernmost dropsondes below $900 \mathrm{hPa}$ has a much lower humidity mixing ratio in the analysis, with a difference of up to $8 \mathrm{~g} / \mathrm{kg}$ (not shown). The lower humidity and $\theta_{\mathrm{e}}$ around $15^{\circ} \mathrm{N}$ in the analysis could be due to spurious drying by analysis increments, caused by a well-known dry humidity bias associated with radiosondes in the region (Bock et al., 2007; Nuret et al., 2008). The $\theta_{\mathrm{e}}$ gradient north of the Sahara is around 0.5 degrees further north in the analysis (Figure $7(\mathrm{~d})$ ) compared with the observations (Figure 7(c)).

Just above the CBL, there is a notable minimum in $\theta_{\mathrm{e}}$ in the lower part of the residual layer, right across the Sahara (apparent in Figure 7(c), for example around $650 \mathrm{hPa}$ at $22^{\circ} \mathrm{N}$ and $700 \mathrm{hPa}$ at $18^{\circ} \mathrm{N}$ ), and this layer corresponds to the low humidity and low dust loading already noted in section 4 (Figure 5(a)). The layer of low $\theta_{\mathrm{e}}$ is qualitatively captured by the analysis. However, the analysis fails to capture the higher $\theta_{\mathrm{e}}$ (around $540 \mathrm{hPa}$ at $22^{\circ} \mathrm{N}$ ) at the top of the residual layer (Figure $7(\mathrm{c})-(\mathrm{d})$ ), due to the model being too dry. The high $\theta_{\mathrm{e}}$ at the top of the atmospheric boundary layer (the top of the residual layer) corresponds to a layer close to saturation, at around $525 \mathrm{hPa}$ (Figure 7(e)). The top of the boundary layer is commonly a level of high relative humidity over the Sahara, and is a preferred level for altocumulus clouds (as discussed by Parker et al. (2005a)), which were observed intermittently during the 17 July flight. The relative humidity in this layer is underestimated in the analysis and located a few tens of $\mathrm{hPa}$ lower. The reasons for the observed humidity stratification of the residual layer, with more humid, high- $\theta_{\mathrm{e}}$ air overlying drier air, are not clear, but the stratification could be related to the detrainment in the upper residual layer of dry convective plumes over the Sahara (Marsham et al., 2008a; Cuesta et al., 2009) or deep moist convective plumes over the Saharan margins (Parker et al., 2005a). It is quite possible that humidity 
(a)

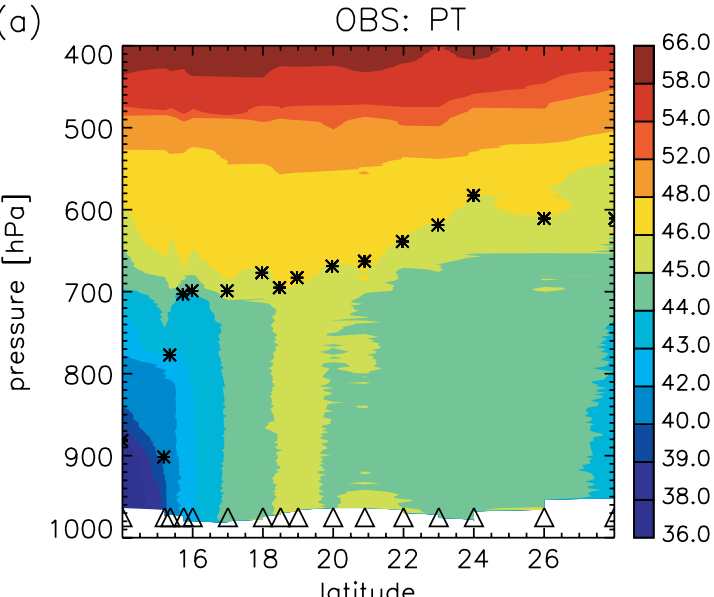

(c)

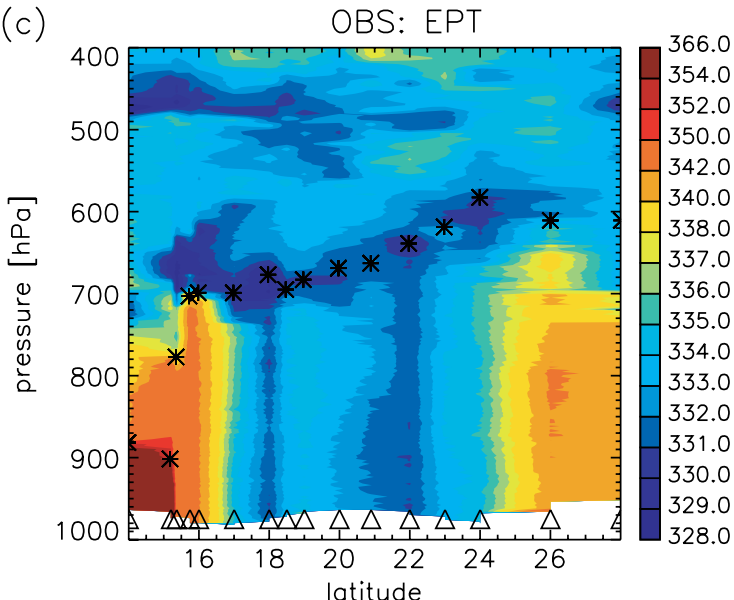

(e)

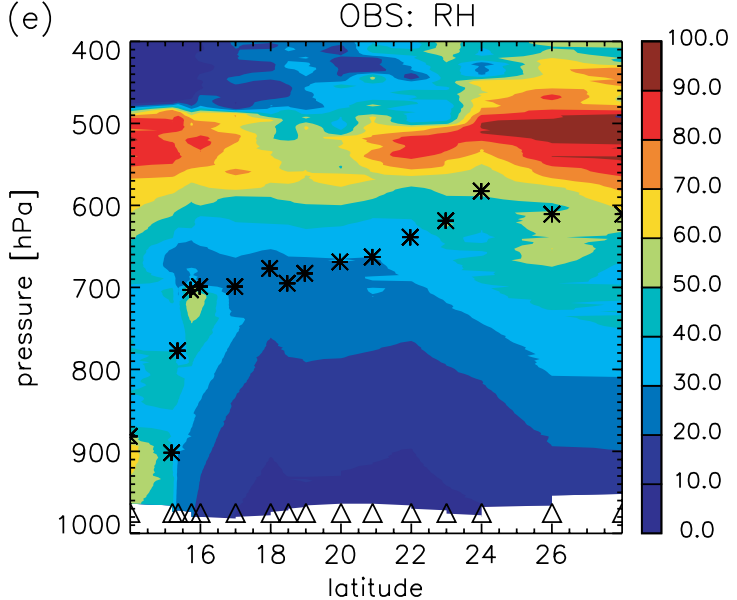

(b)

AN: PT

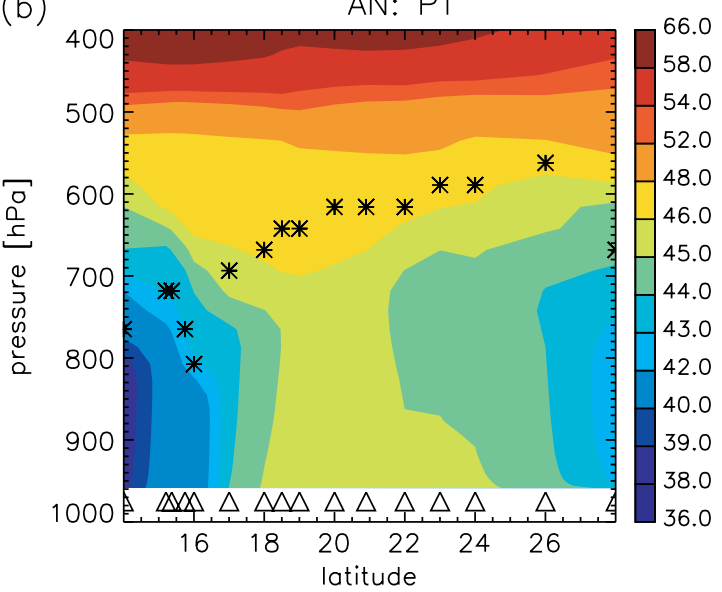

(d)

AN: EPT

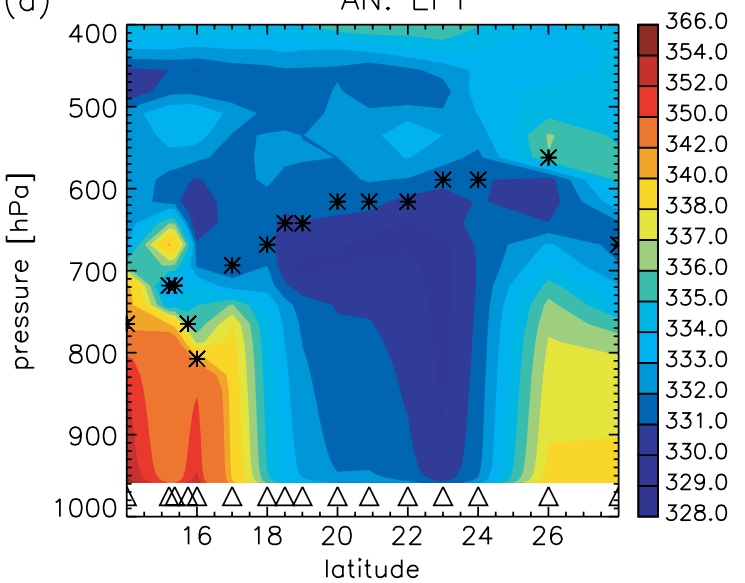

(f)

$\mathrm{AN}: \mathrm{RH}$

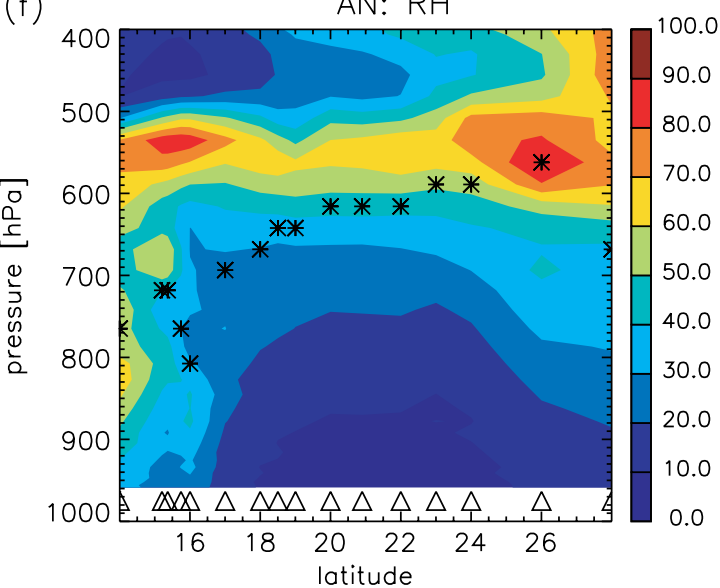

Figure 7. Potential temperature $\left({ }^{\circ} \mathrm{C}\right)$, equivalent potential temperature $(\mathrm{K})$ and relative humidity $(\%)$ computed from (a), (c),(e) the dropsondes and (b),(d),(f) ECMWF analysis for 1500 UTC 17 July. The estimated CBL height is shown by the black stars. White triangles indicate location of dropsonde releases.

errors in this layer could have a significant impact on the radiative flux divergence profile - particularly if clouds occur - and thereby on the diurnal evolution of the CBL; this error is consistent with the analysis being warmer than observations in this case.

The thermodynamics features observed by dropsondes on the 17 July flight have been presented in this section and in section 4 . The winds observed during the flight can be roughly described and illustrated by Figure 2(c)-(d), that shows the flight track capturing mainly the northeasterly flow from the Saharan heat-low western flank, except for the south and north ends of the transect. Indeed, between $14^{\circ} \mathrm{N}$ and $17^{\circ} \mathrm{N}$, the flight captured some of the westerly monsoon flow over the southeastern Saharan heat-low flank. Figure 8 presents the zonal and meridional winds from dropsondes released during the research flight, and the ECMWF analysis (see section 2) at 1500 UTC 17 July 2006, for comparison. At low levels, 


\section{(a) Observed meridional wind (V)}

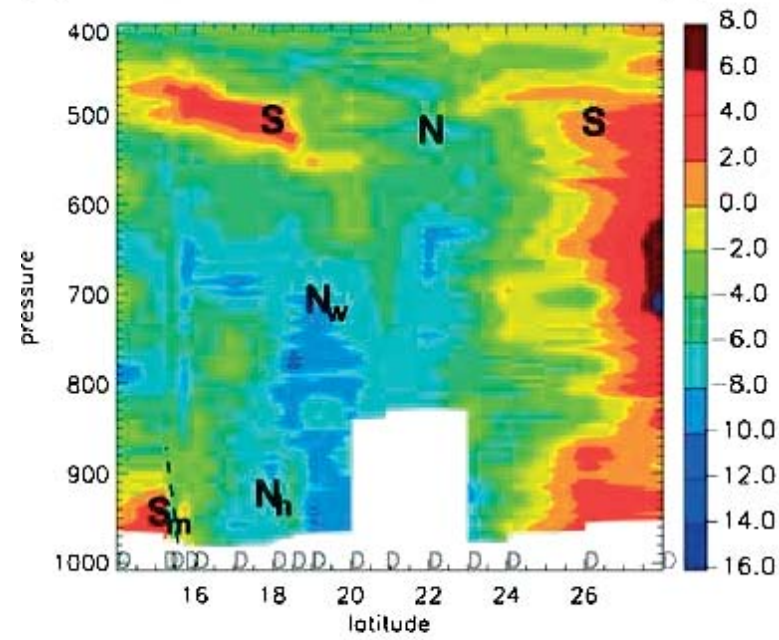

(c) Observed zonal wind (U)

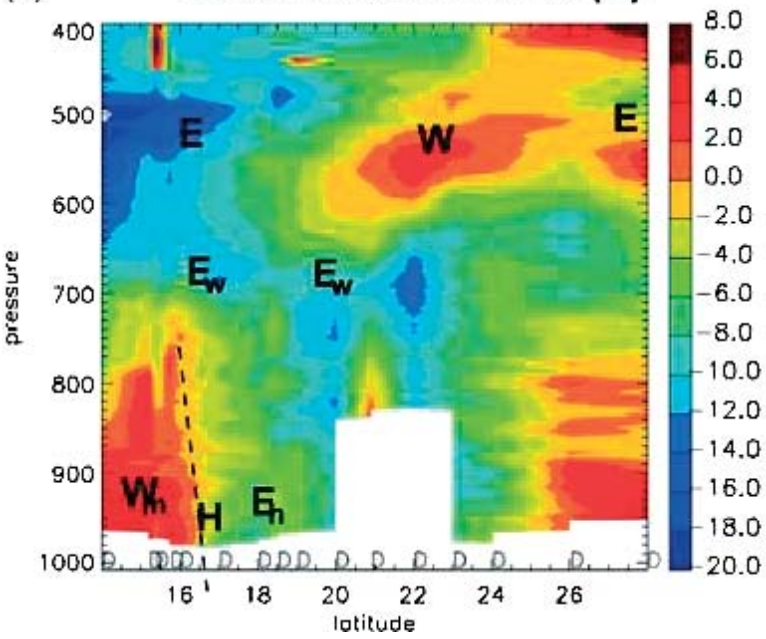

(b) Analysis: V at 15 UTC 17 July 2006

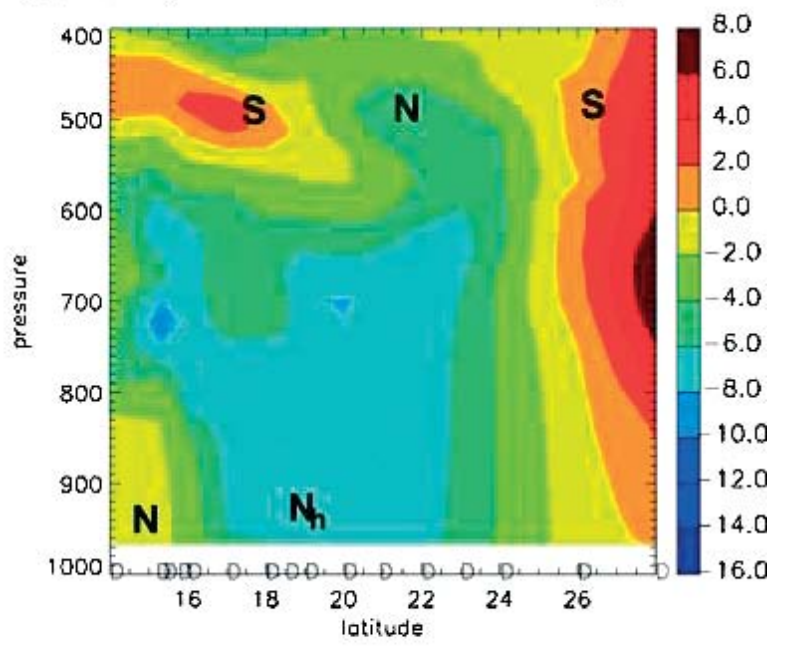

(d) Analysis: U at 15 UTC 17 July 2006

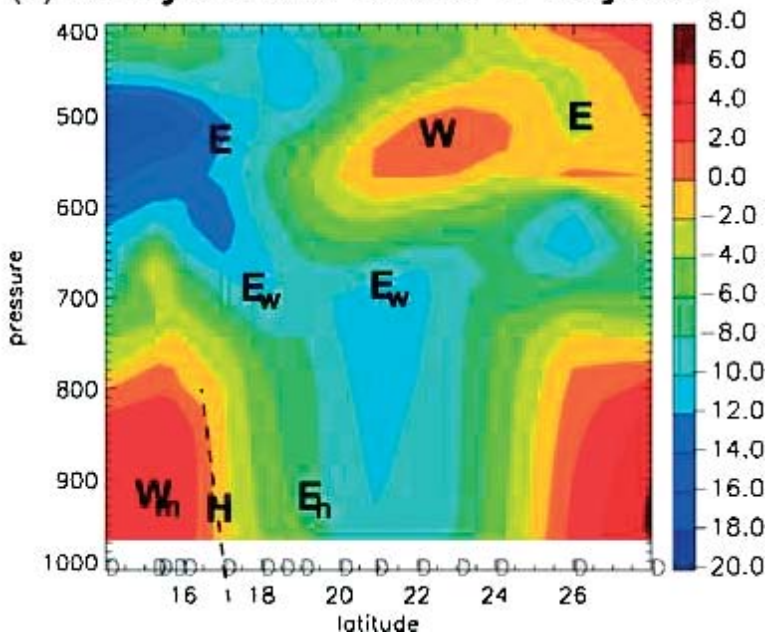

Figure 8. Meridional (a),(b) and zonal (c),(d) wind components $\left(\mathrm{m} \mathrm{s}^{-1}\right.$ ) from dropsondes (a), (c) and ECMWF analysis at 1500 UTC (b),(d) for the FAAM flight of 17 July 2006. Circles on the bottom latitude scale mark the location of the dropsondes. 'N, S, E, W' mean respectively the northerly, southerly, easterly and westerly component of a flow. 'Sm' means south-westerly monsoon flow. 'Nh' and 'Eh' mean respectively the northerly and easterly components of the Harmattan wind. 'Nw' and 'Ew' mean respectively the northerly and easterly components of the African Easterly Wave flow. In (a) the dashed line marks the main convergence line at the ITF. In (c) and (d), the dashed line indicates the axis of the zonal wind-shear with ' $H$ ' the heat-low vortex at this time.

the southwesterly monsoon ('Sm' in Figure 8(a)), which is just captured by the two southernmost dropsondes, is not present in the analysis (Figure 8(b)). Instead the flow is north-westerly at this time. The analysis increments at $950 \mathrm{hPa}$ weaken the northerly flow in the analysis compared with the first guess by between $1 \mathrm{~m} \mathrm{~s}^{-1}$ and $2 \mathrm{~m} \mathrm{~s}^{-1}$ in the two southernmost dropsondes (not shown).

From Figure 2(b)-(c), the ITF is sharply resolved in the dropsonde data, and lies between $15.2^{\circ} \mathrm{N}$ and $15.36^{\circ} \mathrm{N}$ (around $16 \mathrm{~km}$ separation). The $925 \mathrm{hPa}$ dropsonde winds confirm this, with a southerly component of $2.4 \mathrm{~m} . \mathrm{s}^{-1}$ at $15.2^{\circ} \mathrm{N}$ meeting a northerly component of $-4.5 \mathrm{~m} . \mathrm{s}^{-1}$ at $15.36^{\circ} \mathrm{N}$. The southerly component of winds at $15.2^{\circ} \mathrm{N}$ extends in altitude to about $920 \mathrm{hPa}$. However, the flow has a westerly component up to the level of around $800 \mathrm{hPa}$, and up to $17^{\circ} \mathrm{N}$. To the north of the ITF, there is the northeasterly Harmattan flow (see $\mathrm{Nh}$ and $\mathrm{Eh}$ in Figure 8(a)-(b); up to around $650 \mathrm{hPa}$ from $18^{\circ} \mathrm{N}$ to $23^{\circ} \mathrm{N}-\mathrm{Nh}$ and $\mathrm{Eh}$ are respectively the northerly and easterly components of the Harmattan wind) the intensity of which is slightly underestimated in the analysis.

At mid-levels there is northeasterly flow associated with the western flank of an African Easterly Wave trough (see 'Nw' and 'Ew' in Figure $8-\mathrm{Nw}$ and $\mathrm{Ew}$ are the northerly and easterly components of the African Easterly Wave flow, respectively). Both the northerly ('Nw') and easterly winds ('Ew') are stronger in the observations than in the analysis.

At around $500 \mathrm{hPa}$, the flight passed over the centre of the anticyclone, centred around $19^{\circ} \mathrm{N}$ over Mauritania, residing at the top of the warm Saharan boundary layer (e.g. Rácz and Smith, 1999; Spengler and Smith, 2008). The change in the wind direction within the anticyclonic centre (southeast to northwest in Figure 8(a) and (c)) is well represented in the analysis (Figure 8(b) and (d)). To the north - between $25^{\circ} \mathrm{N}$ and $28^{\circ} \mathrm{N}$ - the flow becomes southerly as part of the eastern side of the high-pressure system over Algeria and Morocco. 


\section{Discussion and conclusions}

This paper makes use of the measurements collected during the AMMA-SOP 2006 campaign and uses several sources of data to document the Saharan atmospheric boundary layer and Saharan heat-low. Radiosoundings, satellite images (MSG/SEVIRI and CALIPSO/CALIOP) and airborne measurements performed with both Doppler lidar and dropsondes have been exploited to give a description of the Saharan heat-low on 14 and 17 July 2006, immediately following the monsoon onset date specified by Janicot et al. (2008). Although the instrumentation of the two flights was not the same, the combination of a morning (14 July) and afternoon (17 July) flight gives us observations at two important times in the diurnal cycle of the Saharan heat-low, with which to evaluate the diurnal cycle in ECMWF analyses. As far as the authors are aware, the airborne measurements during this AMMA campaign give the first complete north-south transects of the Saharan heat-low structures and the planetary boundary layer over the Sahara.

The diurnal cycle of the Saharan atmospheric boundary layer has been highlighted by the radiosonde data, and its signature is seen in the vertical structure of the dropsonde profiles. The widespread separation of the Saharan atmospheric boundary layer into an active CBL and a more laminar residual layer has been described, and has been shown to be a structure occurring more than $25 \%$ of the time at 1200 UTC during July 2006. The $\mathrm{CBL}$ in the morning behaves as an internal layer growing by entrainment of air from a residual layer above, and the process is sufficiently slow that the residual layer persisted until mid-afternoon at all locations on the transect of 17 July. This has been confirmed by analysing the July 2006 radiosonde data recorded four times per day at Tamanrasset; in 1200 UTC observations a split profile is common, and sometimes the residual layer persists to 1800 UTC. CALIPSO/CALIOP images have confirmed also the stratification characteristics of the Saharan heatlow system, with a persistent residual layer. In short, the deep, well-mixed Saharan atmospheric boundary layer becomes dominant only in the afternoon, and on some days does not occur at all. The representation of this process in models is profoundly important for the correct representation of humidity and aerosol transport, each of great importance to the regional and global climate.

Figure 9 gives a schematic south-north vertical section through the $\mathrm{CBL}$ and residual layer, together forming the Saharan Atmospheric Boundary Layer (SABL). This figure should be seen as a northward, Saharan extension of the schematic developed by Parker et al. (2005a) for the West African monsoon. As in the former paper, the bold, solid lines indicate the boundaries of 'Saharan' air,

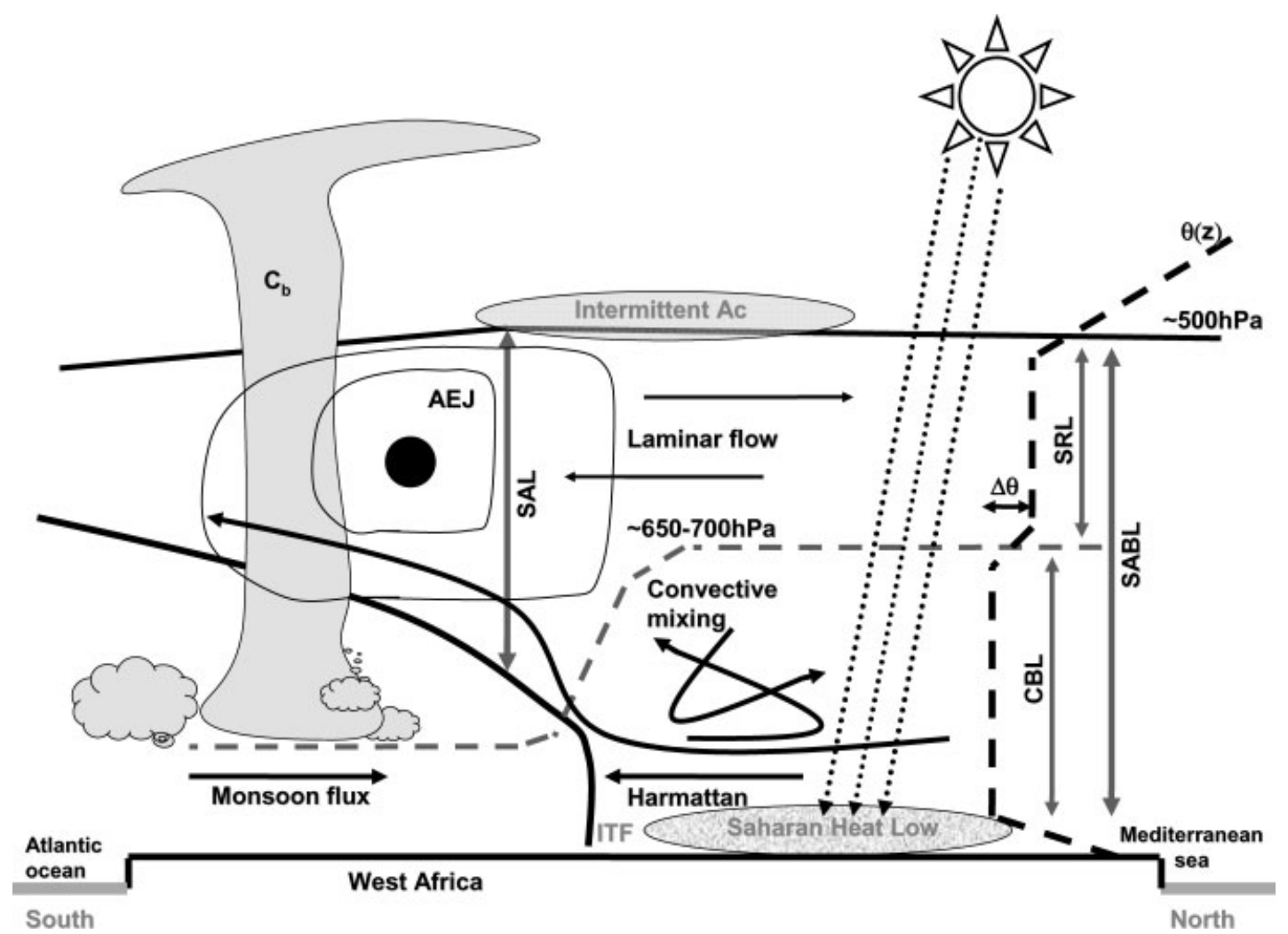

Figure 9. A schematic south-north vertical section of the structure and mixing processes of the Convective Boundary Layer (CBL) beneath the Saharan Residual Layer (SRL), together forming the daytime Saharan Atmospheric Boundary Layer (SABL). Bold solid lines mark the extent of air which is thermodynamically connected to the Sahara through common isentropes (see text). The grey dashed line is the top of the daytime CBL and $\Delta \theta$ is the potential temperature difference across the weak stable later separating the CBL and residual layer. The bold dashed line shows the shape of a typical daytime potential temperature profile over the desert. In the SRL, the flow is much less turbulent and more nearly laminar, with distinct layering of atmospheric constituents such as water vapour and dust. The African Easterly Jet (AEJ) is mainly confined to the latitudes south of the ITF. See text for further explanation. 
comprising the whole boundary layer over the desert, and the Saharan air layer (SAL) as it rises over the monsoon layer to the south. Parker et al. (2005a) noted how the height of the daytime CBL increases with latitude, in the opposite sense to the monsoon-layer depth. The present study has confirmed that the CBL depth is not generally equal to the full depth of the Saharan boundary layer, even during the day. The deepest diurnal convective mixing is located mainly over the Saharan heat-low; in the schematic, the turbulent CBL extends up to roughly $650-700 \mathrm{hPa}$, and this is a typical daytime altitude, but on many afternoons, dry turbulent convection will fill the $\mathrm{SABL}$, up to around 550-500 $\mathrm{hPa}$. In the residual layer, the flow is much less turbulent and more nearly laminar, with distinct layering of atmospheric constituents such as water vapour and dust seen in the observations (e.g. Figure 4, Figure 7(c), or the observations of Flamant et al. (2007)). The African Easterly Jet is confined mainly to the latitudes south of the ITF (see Figures 3(c) and 8(c)) and, in contrast to the case-study of Parker et al. (2005a), there is significant easterly wind shear within the SAL both on 14 and 17 July (Figures 3(c) and 8(c)).

Parker et al. (2005a) proposed that due to the low static stability of the Saharan air, the bounds of the SAL (the bold solid lines in Figure 9) can be defined by chosen isentropes. For their case, Parker et al. (2005a) used $313 \mathrm{~K}$ to define the top of the monsoon layer and $319 \mathrm{~K}$ to define the top of the SAL over West Africa, noting that different temperatures would probably be needed for different cases or times in the season. In the case studied here, over a large latitude range from $17^{\circ} \mathrm{N}$ to $24^{\circ} \mathrm{N}$, it seems that the isentrope of virtual potential temperature, $\theta_{\mathrm{v}}=320 \mathrm{~K}$ (close to potential temperature, $\theta=319 \mathrm{~K}$ ) is a reasonable approximation for the top of the CBL, while $\theta_{\mathrm{v}}=322 \mathrm{~K}(\theta \sim 321 \mathrm{~K})$ approximates the top of the residual layer (see Figure 4 ).

The split boundary-layer structure, involving a rather persistent residual layer overlying a daytime CBL, has significance in the study of the poleward moisture transport in the West African monsoon, in longer-range transport into and out of the Sahara, and in representation of the Saharan boundary layer in global climate models, for which boundary-layer mixing processes have some levels of uncertainty. Notably, the transport of aerosols in the Saharan atmospheric boundary layer will depend sensitively on the depth of the CBL during the day. Given the weak inversion separating the $\mathrm{CBL}$ and residual layer, the rate of growth of the CBL may be very sensitive in models to a number of parametrized processes, including surface energy balance, atmospheric composition, cloud, turbulence and entrainment. Further investigation is required now in order to quantify model performance over the diurnal cycle more systematically than has been possible in this paper, to take into account the effects of aerosol and humidity radiative effects, and thereby to improve model performance for the North African region.

Figure 9 is complementary also to the schematic presented by Cuesta et al. (2009), who provide evidence for a set of mechanisms whereby air from the CBL may be transported into the residual layer. Exchange between the residual layer and CBL will change the large-scale transport characteristics of atmospheric constituents - for instance, air entering the residual layer through a hot plume from the CBL may be transported large horizontal distances from its source in the more laminar flow at these higher levels. The observation of stratification in the residual layer, with humid, dusty air overlying a drier, less dusty layer (Figures 4 and 5(a)), is consistent with the observations of Flamant et al. (2007). The stratification may be the result of hot, humid and dusty plumes of air penetrating into the residual layer from the CBL at some remote locations, and passing straight to the top of the residual layer due to the low static stability. As explained by Cuesta et al. (2009), there are a number of candidate processes which can lead to such injection of CBL air into the residual layer. In order to predict the thermodynamics and composition of this region, it will be necessary to evaluate the exchanges which cause this stratification.

A comparison between observations and ECMWF analyses showed that the analyses produced a monsoon layer (cool, moist southwesterly air) and ITF extending too far north (by $0.5^{\circ}$ to $1^{\circ}$ ). Moreover, the monsoon layer in the analysis is not moist enough (possibly due to a radiosonde dry bias) and is too deep. In addition, the region of maximum boundary-layer temperature over the desert seems to be too far north and too broad in the analysis. $\theta_{\mathrm{e}}$ is a critical field in the tropical atmosphere, particularly through its control of convective available potential energy and convective inhibition (Williams and Renno, 1993), which influence the occurrence of deep convection (Emanuel, 1994). These results have indicated that for the 17 July case, the analysed $\theta_{\mathrm{e}}$ in the Saharan CBL was lower than observed, while monsoonal air with high $\theta_{\mathrm{e}}$ value was carrying too far northwards into that CBL. Tompkins et al. (2005a, 2005b) showed also that the ECMWF operational model for 2000 had a systematic tendency to move the ITF too far north, although this was improved by new aerosol representation. The residual layer humidity stratification on 17 July, with a nearsaturated layer at the top of the Saharan atmospheric boundary layer, was underestimated also in the analysis, in horizontal extent and altitude, and this error is likely to feed back on the radiative fluxes in the model.

From the afternoon dropsondes of 17 July, it has been shown that the ECMWF analysis captured the locations of the main wind features accurately, though the strengths of both the southwesterly monsoon flow below $900 \mathrm{hPa}$ and the northeasterly Harmattan winds below $650 \mathrm{hPa}$ were underestimated. Like the afternoon dropsonde data, the lidar data from the morning flight of 14 July showed that the ITF in the model was around 1 degree further north than observed. The lidar winds, which in contrast to the dropsondes were not assimilated by the model, showed that the analysis represented the main airflows accurately, apart from the zone to the southeast of a midlevel trough, for which the southerly component of winds was underestimated by some $8 \mathrm{~m} \mathrm{~s}^{-1}$.

One of the objectives of the 2006 AMMA flights was to explore the impact of land-surface heterogeneity on 


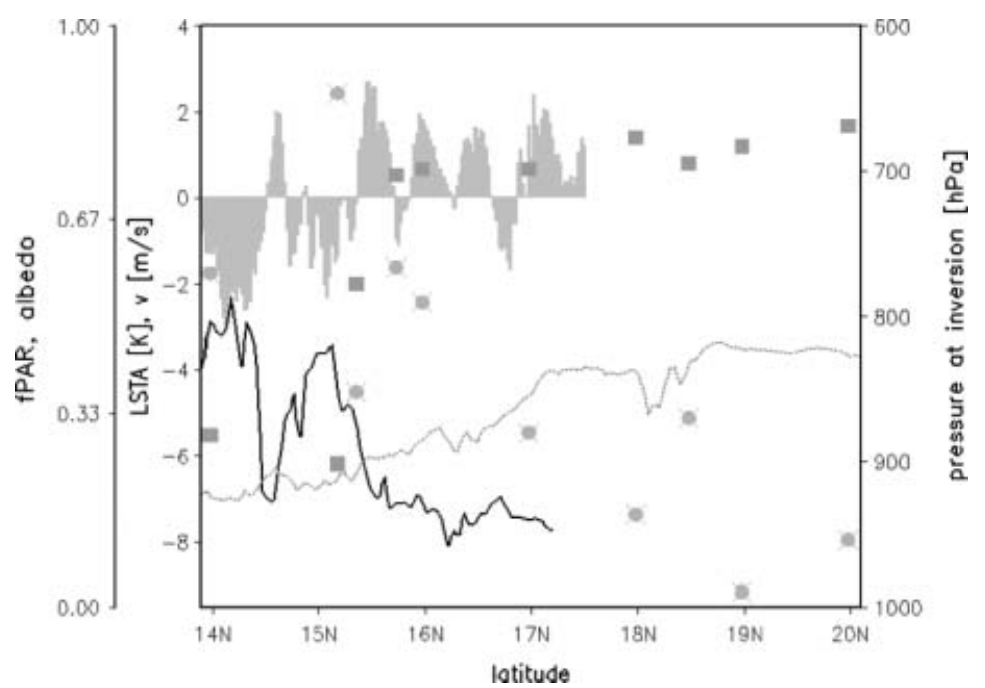

Figure 10. Patterns of Meteosat-derived land-surface temperature anomaly, LSTA (according to Taylor et al. (2007), shaded), Modis fPAR (fractional photosynthetically active radiation - solid line); dropsonde-derived measures of the meridional wind component at $925 \mathrm{hPa}$ (grey circles); and MODIS albedo for the period (dotted line). Squares are pressure at CBL top.

the boundary layer. Although our observational sample of dropsondes is not large enough to test a hypothesis of mesoscale surface control of the CBL in the Sahara rigorously, there are some intriguing coincidences between atmospheric and surface state which are worthy of further investigation. In the CBL, between $17^{\circ} \mathrm{N}$ and $24^{\circ} \mathrm{N}$, there is considerable horizontal variability in the $\theta_{\mathrm{e}}$ field, which could be due to mesoscale surface control on the CBL thermodynamics (e.g. Taylor et al., 2003, 2007 for the Sahel) or due to the random sampling of CBL convective eddies with different $\theta_{\mathrm{e}}$ values (Weckwerth (2000) has noted the $\theta_{\mathrm{e}}$ differences between updraughts and downdraughts in this context). It is intriguing to note that the land-surface conditions along the transect are characterised by a dark surface with low albedo around $18^{\circ} \mathrm{N}$ to $18.4^{\circ} \mathrm{N}$ (Figure 10), close to the rather narrow peak in $\operatorname{CBL} \theta$, and some local variability in winds. Further south, several dropsondes were released over the ITF area (see Table I) to sample the atmosphere over the surface heterogeneity observed also between $15^{\circ} \mathrm{N}$ and $16^{\circ} \mathrm{N}$. In Figure 10 it can be seen that the ITF at the time of the flight was coincident with a marked gradient in land-surface temperature anomaly and vegetation. It is intriguing to question this coincidence: is the land-surface state constraining the ITF to remain at this location, and is the monsoon flux contributing to the maintenance of a vegetation gradient locally? High resolution numerical modelling needs to be carried out to test whether the observed coincidences between land-surface patterns and CBL thermodynamics is statistically coherent over time, and whether they may play a part in the larger-scale dynamics, as proposed by Ramel et al. (2006).

\section{Acknowledgements}

Ch. Messager has been supported by NERC grant NE/B505538/1. The DLR Falcon flights were partly funded by DLR and financial support to the WIND instrument operation was provided by DLR and CNRM. We thank the WIND instrument team for preparing, performing, and analysing these unique measurements: mainly Jean-Pierre Aubagnac (CNRM - Météo France), Alain Dabas (CNRM - Météo France), Patricia Delville (INSU), Marie-Laure Denneulin (CNRM - Météo France), Philippe Drobinski (IPSL), Engelbert Nagel (DLR) and Bernard Romand (LMD). We wish to thank FAAM for the successful conduct of the BAe146 flight. We are grateful to the Centre National d'Études Spatiales (CNES), and the NASA Langley ASDC User Services and Cloud-Aerosols-Water-Radiation Interactions (ICARE) data centre for supplying the CALIPSO data. Additional thanks to LOA (L. Gonzales and C. Daeroo) for AMMA Survey (SEVIRI) data availability. Thanks are due to the staff at Tamanrasset for their high-quality data acquisition in 2006, making extra soundings co-ordinated by Cyrille Flamant (IPSL) and Mohamad Kadi (Algerian ONM and ACMAD). Based on a French initiative, AMMA was built by an international scientific group and is currently funded by a large number of agencies, especially from France, UK, US and Africa. It has been the beneficiary of a major financial contribution from the European Community's Sixth Framework Research Programme. Detailed information on scientific co-ordination and funding is available on the AMMA International web site http://www.ammainternational.org.

\section{References}

Abdou K, Parker DJ, Brooks B, Kalthoff N, Lebel T. 2009. The diurnal cycle of lower boundary layer wind in the West African monsoon. Submitted to Q. J. R. Meteorol. Soc. 136(s1): 66-76.

Bock O, Bouin M-N, Walpersdorf A, Lafore JP, Janicot S, Guichard F, Agusti-Panareda A. 2007. Comparison of ground-based GPS precipitable water vapour to independent observations and NWP model reanalyses over Africa. Q. J. R. Meteorol. Soc. 133: 2011-2027.

Bou Karam D, Flamant C, Knippertz P, Reitebuch O, Pelon J, Chong M, Dabas A. 2008. Dust emissions over the Sahel associated 
with the West African Monsoon intertropical discontinuity region: A representative case-study. Q. J. R. Meteorol. Soc. 134: 621-634. Cakmur RV, Miller RL, Torres O. 2004. Incorporating the effect of small-scale circulations upon dust emission in an atmospheric general circulation model. J. Geophys. Res. 109 D07201, DOI:10.1029/2003JD004067.

Charney JG. 1975. Dynamics of deserts and drought in the Sahel. Q.J. R. Meteorol. Soc. 101: 193-202.

Cuesta J, Edouart D, Mimouni M, Flamant PH, Loth C, Gilbert F, Marnas F, Bouklila A, Kharef M, Ouchène B, Kadi M, Flamant C. 2008. Multiplatform observations of the seasonal evolution of the Saharan atmospheric boundary layer in Tamanrasset, Algeria, in the framework of the African Monsoon Multidisciplinary Analysis field campaign conducted in 2006. J. Geophys. Res. 113: D00C07, DOI: 10.1029/2007JD009417.

Cuesta J, Marsham JH, Parker DJ, Flamant C. 2009. Dynamical mechanisms controlling the vertical redistribution of dust and the thermodynamic structure of the West Saharan atmospheric boundary layer during summer. Atmos. Sci. Lett. 10: 34-42.

Dolman AJ, Gash JHC, Goutorbe J-P, Kerr Y, Lebel T, Prince SD, Stricker JNM. 1997. The role of the land surface in Sahelian climate: HAPEX-Sahel results and future research needs. J. Hydrol. 188-189: 1067-1079.

Drobinski P, Sultan B, Janicot S. 2005a. Role of the Hoggar massif on the West African monsoon onset. Geophys. Res. Lett. 32: L01705, DOI:10.1029/2004GL020710.

Drobinski P, Bastin S, Guenard V, Caccia J-L, Dabas AM, Delville P, Protat A, Reitebuch O, Werner C. 2005b. Summer mistral at the exit of the Rhône valley. Q. J. R. Meteorol. Soc. 131: 353-375.

Dunion JP, Velden CS. 2004. The impact of the Saharan Air Layer on Atlantic tropical cyclone activity. Bull. Am. Meteorol. Soc. 85 353-365.

Eldridge RH. 1957. A synoptic study of West African disturbance lines. O. J. R. Meteorol. Soc. 83: 303-314.

Emanuel KA. 1994. Atmospheric convection. Oxford University Press.

Fernald FG. 1984. Analysis of atmospheric lidar observations: Some comments. Appl. Opt. 23: 652-653.

Fernald FG, Herman BM, Reagan JA. 1972. Determination of aerosol height distributions by lidar. J. Appl. Meteorol. 11: 482-489.

Flamant C, Chaboureau J-P, Parker DJ, Taylor CM, Cammas JP, Bock O, Timouk F, Pelon J. 2007. Airborne observations of the impact of a convective system on the planetary boundary layer thermodynamics and aerosol distribution in the inter-tropical discontinuity region of the West African Monsoon. Q. J. R. Meteorol. Soc. 133: 1175-1189.

Hamilton RA, Archbold JW, Douglas CKM. 1945. Meteorology of Nigeria and adjacent territory. Q. J. R. Meteorol. Soc. 71: 231-264.

Haywood JM, Allan RP, Curverwell I, Slingo A, Milton S, Edwards JE, Clerbaux N. 2005. Can desert dust explain the outgoing longwave radiation anomaly over the Sahara during July 2003? J. Geophys Res. 110: D05105, DOI:10.1029/2004JD005232.

Hoinka KP, de Castro M. 2003. The Iberian Peninsula thermal low. Q. J. R. Meteorol. Soc. 129: 1491-1511.

Hoinka KP, Gaertner M, de Castro M. 2007. Iberian thermal lows in a changed climate. Q. J. R. Meteorol. Soc. 133: 1113-1126.

Janicot S, Sultan B. 2007. 'The large-scale context on the West African Monsoon in 2006.' CLIVAR Newsletter No. 41, 12: 11-17.

Janicot S, Thorncroft CD, Ali A, Asencio N, Berry G, Bock O, Bourles B, Caniaux G, Chauvin F, Deme A, Kergoat L, Lafore JP, Lavaysse C, Lebel T, Marticorena B, Mounier F, Nedelec P, Redelsperger J-L, Ravegnani F, Reeves CE, Roca R, de Rosnay P, Schlager H, Sultan B, Tomasini M, Ulanovsky A, ACMAD forecasters team. 2008. Large-scale overview of the summer monsoon over West Africa during the AMMA field experiment in 2006. Annales Geophysicae 26: 2569-2595.

Kaufman YJ, Tanré D, Léon J-F, Pelon J. 2003. Retrievals of profiles of fine and coarse aerosols using lidar and radiometric space measurements. IEEE Trans. Geosci. Remote Sensing 41: 1743-1754

Knippertz P. 2008. Dust emissions in the West African heat trough - The role of the diurnal cycle and of extratropical disturbances. Meteorol. Z. 17: 553-563.

Lebel T, Parker DJ, Flamant C, Bourles B, Marticorena B, Mougin E, Peugeot C, Haywood JM, Polcher J, Redelsperger J-L, Thorncroft CD. 2009. The AMMA field campaigns: Multiscale and multidisciplinary observations in the West African region. Submitted to Q. J. R. Meteorol. Soc. 136(s1): 8-33.
Lothon M, Saïd F, Lohou F, Campistron B. 2008. Observation of the diurnal cycle in the low troposphere of West Africa. Mon. Weather Rev. 136: $3477-3500$.

Marsham JH, Parker DJ, Grams CM, Johnson BT, Grey WMF, Ross AN. 2008a. Observations of mesoscale and boundary-layer scale circulations affecting dust transport and uplift over the Sahara. Atmos. Chem. Phys. 8: 6979-6993.

Marsham JH, Parker DJ, Grams CM, Taylor CM, Haywood JM. 2008b. Uplift of Saharan dust south of the intertropical discontinuity. $J$. Geophys. Res. 113: D21102, DOI:10.1029/2008JD009844.

May PT. 1995. The Australian nocturnal jet and diurnal variations of boundary-layer winds over Mt. Isa in north-eastern Australia. Q. J. R. Meteorol. Soc. 121: 987-1003.

Nuret M, Lafore J-P, Bock O, Guichard F, Agusti-Panareda A, N'Gamini J-B, Redelsperger J-L. 2008. Correction of humidity bias for Vaisala RS80-A sondes during the AMMA 2006 Observing Period. J. Atmos. Oceanic Technol. 25: 2152-2158.

Oke TR. 1988. Boundary layer climates. Methuen: New York.

Parker DJ, Thorncroft CD, Burton RR, Diongue-Niang A. 2005a. Analysis of the African easterly jet, using aircraft observations from the JET2000 experiment. O. J. R. Meteorol. Soc. 131: 1461-1482.

Parker DJ, Burton RR, Diongue-Niang A, Ellis RJ, Felton M, Taylor CM, Thorncroft CD, Bessemoulin P, Tompkins AM. 2005b. The diurnal cycle of the West African monsoon circulation. $Q$. J.R. Meteorol. Soc. 131: 2839-2860.

Parker DJ, Fink A, Janicot S, Ngamini J-B, Douglas M, Afiesimama E, Agusti-Panareda A, Beljaars A, Dide F, Diedhiou A, Lebel T, Polcher J, Redelsperger J-L, Thorncroft CD, Wilson GA. 2008. The AMMA radiosonde program and its implications for the future of atmospheric monitoring over Africa. Bull. Am. Meteorol. Soc. 89: $1015-1027$

Rácz Z, Smith RK. 1999. The dynamics of heat lows. Q. J. R. Meteorol. Soc. 125: 225-252.

Ramel R, Gallée H, Messager C. 2006. On the northward shift of the West African monsoon. Clim. Dyn. 26: 429-440.

Redelsperger J-L, Thorncroft CD, Diedhiou A, Lebel T, Parker DJ, Polcher J. 2006. African Monsoon Multidisciplinary Analysis: An international research project and field campaign. Bull. Am. Meteorol. Soc. 87: 1739-1746.

Reitebuch O, Werner C, Leike I, Delville P, Flamant PH, Cress A, Engelbart D. 2001. Experimental validation of wind profiling performed by the airborne $10-\mu \mathrm{m}$ heterodyne Doppler lidar WIND. J. Atmos. Oceanic Technol. 18: 1331-1344.

Reitebuch O, Volkert H, Werner C, Dabas A, Delville P, Drobinski P, Flamant PH, Richard E. 2003. Determination of airflow across the Alpine ridge by a combination of airborne Doppler lidar, routine radiosounding and numerical simulation. Q. J. R. Meteorol. Soc. 129: $715-727$.

Rodwell MJ, Jung T. 2008. Understanding the local and global impacts of model physics changes: An aerosol example. Q.J. R. Meteorol. Soc. 134: 1479-1497.

Spengler T, Smith RK. 2008. The dynamics of heat lows over flat terrain. Q. J. R. Meteorol. Soc. 134: 2157-2172.

Sultan B, Janicot S. 2000. Abrupt shift of the ITCZ over West Africa and intra-seasonal variability. Geophys. Res. Lett. 27: 3353-3356.

Sultan B, Janicot S. 2003. The West African monsoon dynamics. Part II: The 'preonset' and 'onset' of the summer monsoon. J. Climate 16: $3407-3427$

Taylor CM, Ellis RJ, Parker DJ, Burton RR, Thorncroft CD. 2003. Linking boundary-layer variability with convection: A case-study from JET2000. Q. J. R. Meteorol. Soc. 129: 2233-2253.

Taylor CM, Parker DJ, Harris PP. 2007. An observational case study of mesoscale atmospheric circulations induced by soil moisture. Geophys. Res. Lett. 34: L15801, DOI:10.1029/2007GL030572.

Tompkins AM, Cardinali C, Morcrette J-J, Rodwell M. 2005a. Influence of aerosol climatology on forecasts of the African Easterly Jet. Geophys. Res. Lett. 32: L10801, DOI:10.1029/2004GL022189.

Tompkins AM, Diongue-Niang A, Parker DJ, Thorncroft CD. 2005b. The African easterly jet in the ECMWF Integrated Forecast System: 4D-Var analysis. Q. J. R. Meteorol. Soc. 131: 2861-2885.

Walker J, Rowntree PR. 1977. Effects of soil moisture on circulation and rainfall in a tropical model. Q. J. R. Meteorol. Soc. 103: 29-46. Washington R, Todd MC, Engelstaedter S, Mbainayel S, Mitchell F. 2006. Dust and the low-level circulation over the Bodélé depression, Chad: Observations from BoDEx 2005. J. Geophys. Res. 111: D03201, DOI:10.1029/2005JD006502.

Weckwerth TM. 2000. The effect of small-scale moisture variability on thunderstorm initiation. Mon. Weather Rev. 128: 4017-4030. 
Williams E, Renno N. 1993. An analysis of the conditional instability of the tropical atmosphere. Mon. Weather Rev. 121: 21-36.

Winker DM, Pelon J, McCormick MP. 2003. The CALIPSO mission: Spaceborne lidar for observation of aerosols and clouds. Pp 1-11 in Proc. Conference on Lidar Remote Sensing for Industry and Environment Monitoring III, Singh UN, Itabe T, Lui Z (eds). Proc. SPIE 4893: DOI: $10.1117 / 12.466539$.

Winker DM, Hunt WH, McGill MJ. 2007. Initial performance assessment of CALIOP. Geophys. Res. Lett. 34: L19803, DOI:10.1029/2007GL030135.
Winker DM, Vaughan MA, Omar A, Hu Y, Powell KA, Liu Z, Hunt WH, Young SA. 2009. Overview of the CALIPSO mission and CALIOP data processing algorithms. J. Atmos. Oceanic Technol., DOI:10.1175/2009JTECHA1281.1, in press.

Young SA, Winker D, Vaughan MA, Hu Y, Kuehn RE. 2008. 'Part 4: Extinction retrieval algorithms.' CALIOP Algorithm Theoretical Basis Document PC-SCI-202 Part 4, Release 1.0 on 28 January 2008 available on http://www-calipso.larc.nasa.gov/resources/pdfs/PCSCI-202_Part4_v1.0.pdf. 